\title{
The Value of Concentrating Solar Power and Thermal Energy Storage
}

Technical Report NREL-TP-6A2-45833

February 2010

Ramteen Sioshansi

The Ohio State University

Columbus, Ohio

Paul Denholm

National Renewable Energy Laboratory

Golden, Colorado
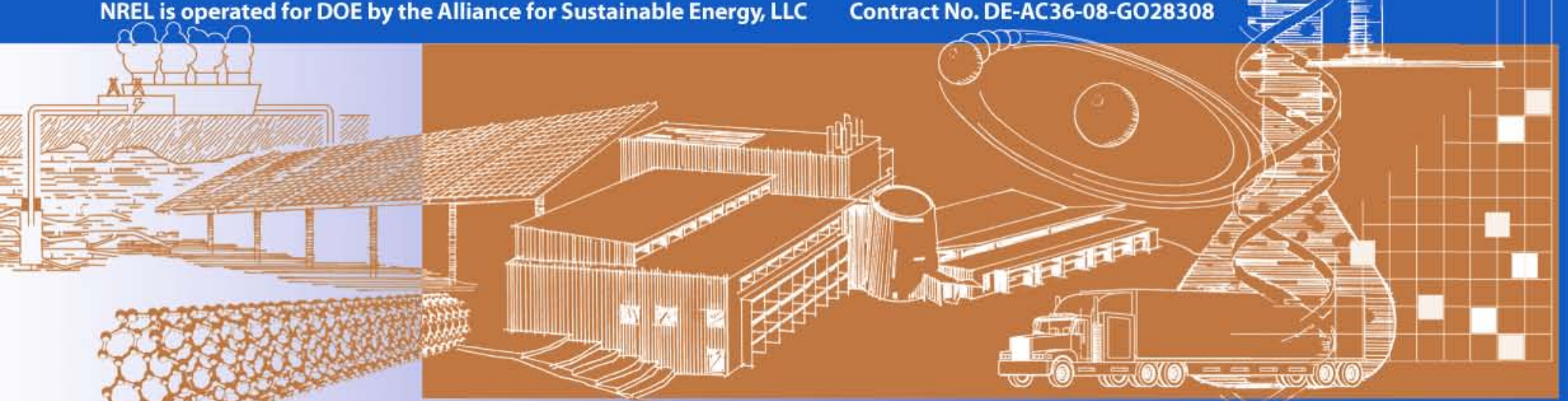


\section{The Value of Concentrating Solar Power and Thermal Energy Storage}

Technical Report NREL-TP-6A2-45833

February 2010

Ramteen Sioshansi

The Ohio State University

Columbus, Ohio

Paul Denholm

National Renewable Energy Laboratory

Golden, Colorado

Prepared under Task No. CP09.3201

National Renewable Energy Laboratory

1617 Cole Boulevard, Golden, Colorado 80401-3393

303-275-3000 • www.nrel.gov

NREL is a national laboratory of the U.S. Department of Energy

Office of Energy Efficiency and Renewable Energy

Operated by the Alliance for Sustainable Energy, LLC

Contract No. DE-AC36-08-GO28308

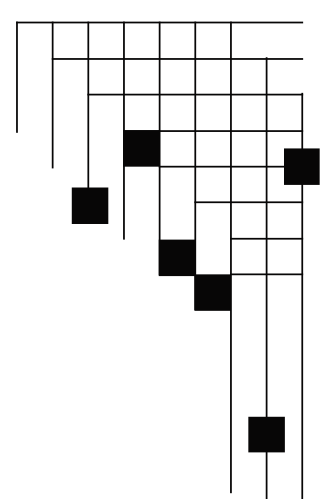




\section{NOTICE}

This report was prepared as an account of work sponsored by an agency of the United States government. Neither the United States government nor any agency thereof, nor any of their employees, makes any warranty, express or implied, or assumes any legal liability or responsibility for the accuracy, completeness, or usefulness of any information, apparatus, product, or process disclosed, or represents that its use would not infringe privately owned rights. Reference herein to any specific commercial product, process, or service by trade name, trademark, manufacturer, or otherwise does not necessarily constitute or imply its endorsement, recommendation, or favoring by the United States government or any agency thereof. The views and opinions of authors expressed herein do not necessarily state or reflect those of the United States government or any agency thereof.

Available electronically at http://www.osti.gov/bridge

Available for a processing fee to U.S. Department of Energy and its contractors, in paper, from:

U.S. Department of Energy

Office of Scientific and Technical Information

P.O. Box 62

Oak Ridge, TN 37831-0062

phone: 865.576 .8401

fax: 865.576 .5728

email: mailto:reports@adonis.osti.gov

Available for sale to the public, in paper, from:

U.S. Department of Commerce

National Technical Information Service

5285 Port Royal Road

Springfield, VA 22161

phone: 800.553.6847

fax: 703.605.6900

email: orders@ntis.fedworld.gov

online ordering: http://www.ntis.gov/ordering.htm 


\section{Abstract}

This paper examines the value of concentrating solar power (CSP) and thermal energy storage (TES) in four regions in the southwestern United States. Our analysis shows that TES can increase the value of CSP by allowing more thermal energy from a CSP plant's solar field to be used, by allowing a CSP plant to accommodate a larger solar field, and by allowing CSP generation to be shifted to hours with higher energy prices. We analyze the sensitivity of CSP value to a number of factors, including the optimization period, price and solar forecasting, ancillary service sales, capacity value and dry cooling of the CSP plant. We also discuss the value of CSP plants and TES net of capital costs. 


\section{Table of Contents}

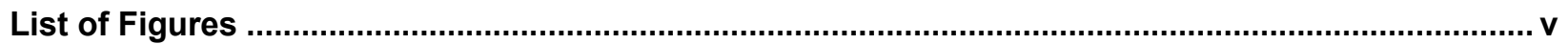

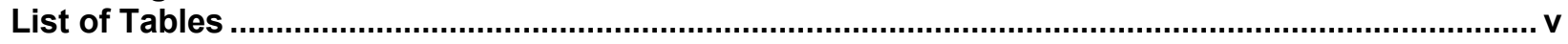

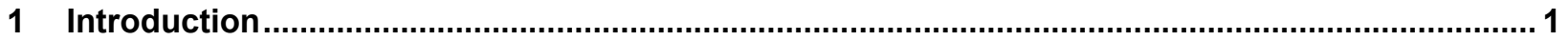

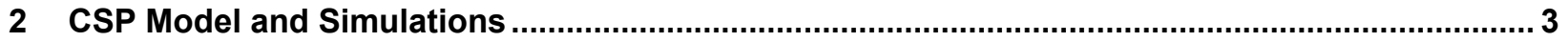

3 Operating Profits of CSP Plants with TES in Energy-Only Markets ........................................... 7

4 Sensitivity of CSP Profits to Base Case Assumptions.............................................................. 13

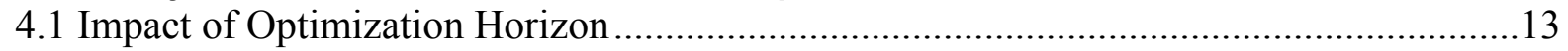

4.2 Impact of Solar Availability and Energy Price Forecasting ....................................... 14

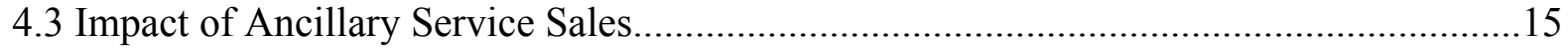

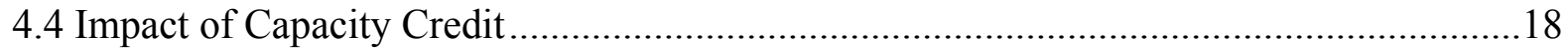

4.5 Impact of Power Block Dry Cooling .......................................................................... 18

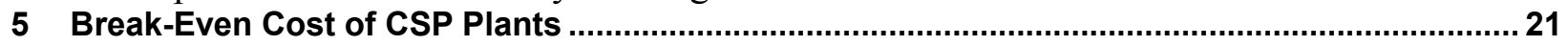

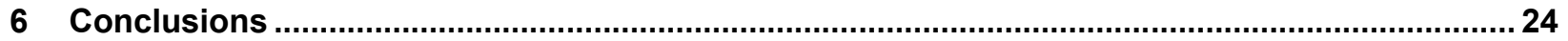

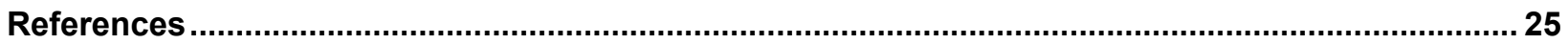




\section{List of Figures}

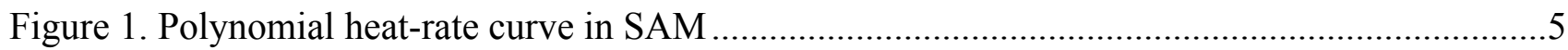

Figure 2. Polynomial representation of HTF parasitics in SAM and piecewise-linear approximation in dispatch model....................................................................................6

Figure 3. Polynomial representation of power block parasitics in SAM and piecewise-linear approximation in dispatch model....................................................................................6

Figure 4. Sample dispatch of a CSP plant with six hours of TES and a solar multiple of 2.0 at

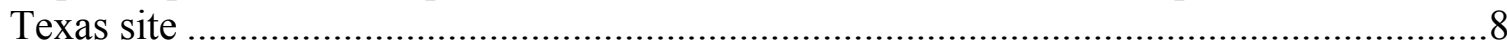

Figure 5: Annual operating profits of a CSP plant at Arizona site ..................................................

Figure 6: Annual operating profits of a CSP plant at Daggett site ....................................................

Figure 7: Annual operating profits of a CSP plant at New Mexico site ............................................10

Figure 8: Annual operating profits of a CSP plant at Texas site ………...........................................10

Figure 9. Average selling price of energy $(\$ / \mathrm{MWh})$ and solar field energy wasted (GWh-t) for a CSP plant at Texas site with solar multiple of 2.0 ........................................................12

Figure 10. Marginal annual value of each incremental hour of storage for a CSP plant at Texas

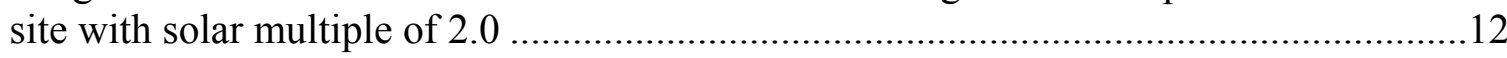

Figure 11. Increase in annual operating profits of a CSP plant at Texas site from using weeklong as opposed to daylong optimization period

Figure 12. Annual operating profits earned by a CSP plant at Texas site using daily backcasting technique

Figure 13. Sample dispatch of a CSP plant with 8 hours of TES and a solar multiple of 2.4 at Texas site when energy and spinning reserve sales are co-optimized...............................16

Figure 14. Increase in annual operating profits of a CSP plant at the Daggett site if spinning reserves can be sold .................................................................................................

Figure 15. Increase in annual operating profits of a CSP plant at the Texas site if spinning

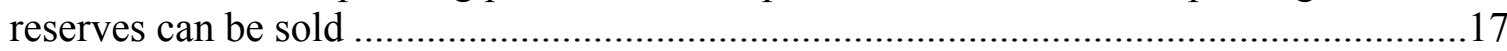

Figure 16: Annual operating profit reduction of a dry-cooled CSP plant at Texas site........................19

Figure 17. Net operating profits lost from dry- as opposed to wet-cooled CSP plants with a solar

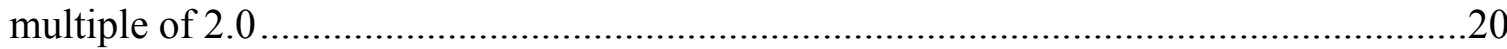

Figure 18. Net energy production lost from dry- as opposed to wet-cooled CSP plants with a

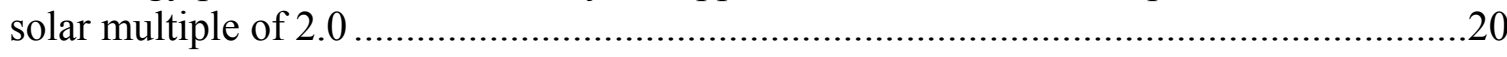

\section{List of Tables}

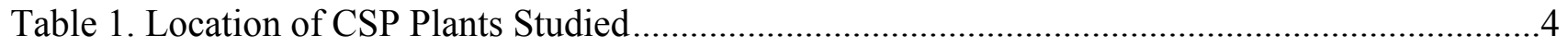

Table 2: Solar Energy Available and Average Price of Energy for Different CSP Sites .....................11

Table 3: Year-1 Break-Even Cost and Return on Investment of TES Using Base Case Profit and

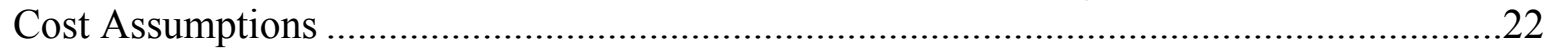

Table 4: Year-1 Break-Even Cost of TES (\$ million) with Spinning Reserves Sales and Capacity

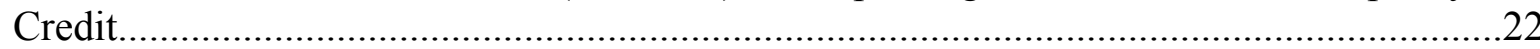

Table 5: Return on Investment of TES with Spinning Reserves Sales and Capacity Credit and a $10 \%$ ITC 


\section{Introduction}

Recent and ongoing improvements in thermal solar generation technologies coupled with the need for more renewable sources of energy have increased interest in concentrating solar thermal power (CSP). Unlike solar photovoltaic (PV) generation, CSP uses the thermal energy of sunlight to generate electricity. Two common designs of CSP plants - parabolic troughs and power towers - concentrate sunlight onto a heat-transfer fluid (HTF), which is used to drive a steam turbine. An advantage of CSP over non-dispatchable renewables is that it can be built with thermal energy storage (TES), which can be used to shift generation to periods without solar resource and to provide backup energy during periods with reduced sunlight caused by cloud cover. ${ }^{1}$ The storage medium is typically a molten salt, which has extremely high storage efficiencies in demonstration systems.

Adding TES provides several additional sources of value to a CSP plant. First, unlike a plant that must sell electricity when solar energy is available, a CSP plant with TES can shift electricity production to periods of highest prices. Second, TES may provide firm capacity to the power system, replacing conventional power plants as opposed to just supplementing their output. Finally, the dispatchability of a CSP plant with TES can provide high-value ancillary services such as spinning reserves. ${ }^{2}$

Building a CSP plant with TES introduces several sizing options as the plant essentially consists of three independent but interrelated components that can be sized differently: the power block, the solar field, and the thermal storage tank. The size of the power block is the rated power capacity of the steam turbine, and it is typically measured by the rated input of the power block in megawatts of thermal energy (MW-t) or in the rated output of the power block in megawatts of electric energy (MW-e).

The size of the solar field, in conjunction with solar irradiance, determines the amount of thermal energy that will be available to the power block. The sizing of the solar field is important because the relative size of the solar field and power block will determine the capacity factor of the CSP plant and the extent to which thermal energy will be wasted. Undersizing the solar field will result in an underused power block and a low capacity factor for the CSP plant, because of the lack of thermal energy during all hours but those with the highest solar resource. ${ }^{3}$ An oversized solar field, on the other hand, will tend to result in thermal energy being wasted because the power block will not have sufficient capacity to use the thermal energy from the solar field in many hours. The size of the solar field can either be measured in the actual area of the field or by using the solar multiple, which normalizes the size of the solar field in terms of the power block size. A solar field with a solar multiple of 1.0 is sized to provide sufficient energy to operate the power block at its rated capacity under reference conditions. The area of a solar field with a higher or lower solar multiple will be scaled linearly; i.e. a field with a solar multiple of 2.0 will cover twice the area of a field with a solar multiple of 1.0.

\footnotetext{
${ }^{1}$ The HTF in a CSP plant will also have some thermal inertia that can help the CSP plant "ride out" a brief reduction in sunlight from a passing cloud.

${ }^{2}$ This is described in detail in section 4.3.

${ }^{3}$ A CSP plant can be designed with a fossil-fueled backup system. With such a design, natural gas or another fuel can be used to supplement solar thermal energy. Because our interest is in renewable resources, we focus on a pure CSP plant.
} 
The size of storage determines both the thermal power capacity of the heat exchangers between the storage tank and the HTF (measured in MW-t) and the total energy capacity of the storage tank. While the energy capacity of the storage tank can be measured in MWh-t, measuring it in terms of the number of hours of storage is often more convenient. We define the storage capacity as the number of hours that the storage tank can be charged at maximum capacity, which is very similar to the number of hours of discharge capacity because the roundtrip efficiency of the TES is about $98.5 \%$. It is worth noting that another benefit of building a CSP plant with TES is that storage can allow the plant to be built with a larger solar field because excess thermal energy can be placed into storage for use later.

For a merchant CSP developer, the decision to build and the choice of the size of a CSP plant will be governed not only by the amount of solar energy available but also by the pattern (coincidence) of solar resource and by electricity prices. Clearly, high electricity prices and an abundance of solar resource are necessary for CSP to be economic, but a lack of correlation between solar availability and electricity prices can make CSP economically unattractive. TES can improve the economics by shifting generation to higher-priced hours, but this adds capital costs and some efficiency losses in the storage cycle.

In this paper, we examine the value of adding TES to CSP plants in a number of power systems in the southwestern United States. Using a model that optimally dispatches CSP with TES into existing electricity markets, we examine the potential operating profits (i.e., net revenues from energy sales, not accounting for fixed capital costs) that a CSP plant can earn. We show how these profits vary as a function of plant size. We also show the sensitivity of operating profits to different assumptions, including the possibility of selling ancillary services, the optimization process used, and the use dry rather than wet cooling. We show that while the current cost of CSP technologies make them uneconomic based on energy value alone, addition of TES improves the economics of CSP. We also show that when the value of ancillary services and capacity are taken into account, TES and CSP can be economic even with current technology costs.

The remainder of this paper is organized as follows: Section 2 describes our model and the assumptions underlying our analysis. Section 3 presents our analysis of CSP operating profits under the base scenario while Section 4 discusses the sensitivity of those profits to these assumptions. Section 5 discusses the net profitability of TES and CSP plants and Section 6 concludes. 


\section{CSP Model and Simulations}

We model the capabilities and costs of CSP plants using a mixed-integer program (MIP) that is based on the Solar Advisor Model (SAM) developed by the National Renewable Energy Laboratory (NREL) ${ }^{4}$ SAM is a software package that can model in detail the hourly energy production of PV, concentrating PV, and CSP plants, with different configurations and in different locations. This production data can be coupled with cost data to compute different economic benchmarks for solar systems, such as the levelized cost of energy. SAM also has some capabilities to optimize the dispatch of a CSP plant with TES by using heuristic "time-ofday" type rules. These heuristics can be used to compare the cost of energy from a CSP plant to other conventional generators.

Unlike SAM, our MIP is formulated to fully optimize the dispatch of a CSP plant to maximize net revenues from energy sales rather than using heuristic rules. ${ }^{5}$ The dispatch assumes the CSP plant is a price-taking generator that treats prices as fixed. Because we model only a single CSP plant, this price-taking assumption is reasonable, as the operation of the CSP plant would have at most a marginal impact on the dispatch of other generators. The capabilities and costs of the CSP plants are simulated using the baseline CSP system in SAM, which has a wet-cooled power block with a design capacity of $110 \mathrm{MW}$-e We simulate a set of CSP plant sizes with solar multiples ranging between 1.5 and 2.7 and between zero and twelve hours of TES.

SAM models the three components of a CSP plant - the solar field, TES system, and power block - on an hourly basis, and we use SAM for developing our CSP dispatch model. The solar field model determines the amount of thermal energy (measured in MWh-t) collected by the field that is available to be put into the TES or power block. This available thermal energy is determined by ambient sunlight as well as solar field size and the efficiencies of the components such as concentrators, collectors, and the HTF used in the solar field. We use this hourly available solar data as an input to our model.

We model CSP plants in four different locations, which are summarized in Table 1. The plants were all simulated using energy price and solar data from 2005. The solar data were obtained from NREL's Renewable Planning Model. ${ }^{67}$ For the Daggett and Texas CSP plants, hourly realtime energy and day-ahead ancillary service price data from their respective wholesale electricity markets were used. In the case of Daggett, price data from the California Independent System Operator (CAISO) SP15 zone is used, whereas the Texas plant uses prices from the Electricity Reliability Council of Texas (ERCOT) western zone. For the locations in Arizona and New Mexico, load lambda data from 2005 for the incumbent utilities-Arizona Public Service (APS) and Public Service New Mexico (PNM), respectively_-were used. Load lambda data were obtained from Form 714 filings with the Federal Energy Regulatory Commission.

\footnotetext{
${ }^{4}$ See Gilman et al. (2008) for a detailed description of SAM and its capabilities.

${ }^{5}$ For purposes of comparison, the default heuristic dispatch rule in SAM is able to capture between $87 \%$ and $94 \%$ of the operating profits that our MIP model earns with a CSP plant with a solar multiple of 2.0 and six hours of TES.

${ }^{6}$ Available at http://rpm.nrel.gov/

${ }^{7}$ Solar direct normal irradiance in 2005 at the sites we consider was approximately $1-4 \%$ below the average over the period 1998-2006.
} 
Table 1. Location of CSP Plants Studied

\begin{tabular}{lll}
\hline CSP Site & Location & Price Data \\
\cline { 2 - 3 } Arizona & Gila Bend, Arizona $\left(32^{\circ} 57^{\prime} \mathrm{N}, 112^{\circ} 57^{\prime} \mathrm{W}\right)$ & APS Load Lambda \\
Daggett & Daggett, California $\left(34^{\circ} 51^{\prime} \mathrm{N}, 116^{\circ} 51^{\prime} \mathrm{W}\right)$ & CAISO SP15 Zone \\
New Mexico & Southern New Mexico $\left(31^{\circ} 39^{\prime} \mathrm{N}, 108^{\circ} 39^{\prime} \mathrm{W}\right)$ & PNM Load Lambda \\
Texas & Western Texas $\left(32^{\circ} 21^{\prime} \mathrm{N}, 102^{\circ} 21^{\prime} \mathrm{W}\right)$ & ERCOT West Zone \\
\hline
\end{tabular}

The TES is modeled as a stock and flow system with losses, which accounts for the loss of thermal energy that is kept in storage over time. Furthermore, energy that goes through the storage cycle will experience some additional losses because of inefficiencies in heat transfer from the solar field to the TES and then to the power block. We assume that hourly energy losses in TES will be $0.031 \% .{ }^{8}$ SAM models efficiency losses from using TES by multiplying the gross output of the power block by a term that is a non-linear function of the fraction of thermal energy delivered to the power block that comes from TES. To maintain linearity of our MIP model, we instead assume that $1.5 \%$ of energy taken through the storage cycle will be lost-which roughly approximates the non-linear term in SAM. We assume the TES system is sized to allow the power block to operate at its maximum load using energy from storage alone. For the $110 \mathrm{MW}-\mathrm{e}$ power block, this corresponds to a power capacity of approximately $340 \mathrm{MW}-$ t. We also assume that the TES system has the same power capacity for charging and discharging.

The power block is modeled using a heat-rate curve, which gives gross electric output as a function of thermal energy put into the power block. SAM uses a third-order polynomial heat rate curve, which is shown in Figure 1. The figure shows that the polynomial has very little curvature, and for this reason we approximate the curve as a linear function in our dispatch model. As is suggested in the figure, SAM allows the power block to be operated at up to $115 \%$ of its design capacity (126.5 MW-e), and we assume that the power block can generate up to this level. We further assume that the power block must be run at a minimum load of $40 \%$ of its design point (i.e., gross generation of at least $44 \mathrm{MW}-\mathrm{e}$ ) whenever the power block is operating. We further require that the power block be online for a minimum of two consecutive hours whenever it is started up, and we assume that $58.3 \mathrm{MWh}-\mathrm{t}$ of thermal energy is required to start up the power block, ${ }^{9}$ which takes one hour.

\footnotetext{
${ }^{8}$ Based on tests conducted of storage efficiencies from the Solar Two CSP plant in California

${ }^{9} 58.3 \mathrm{MWh}-\mathrm{t}$ corresponds to $20 \%$ of the energy required to run the power block at its design point of $110 \mathrm{MWh}-\mathrm{e}$.
} 


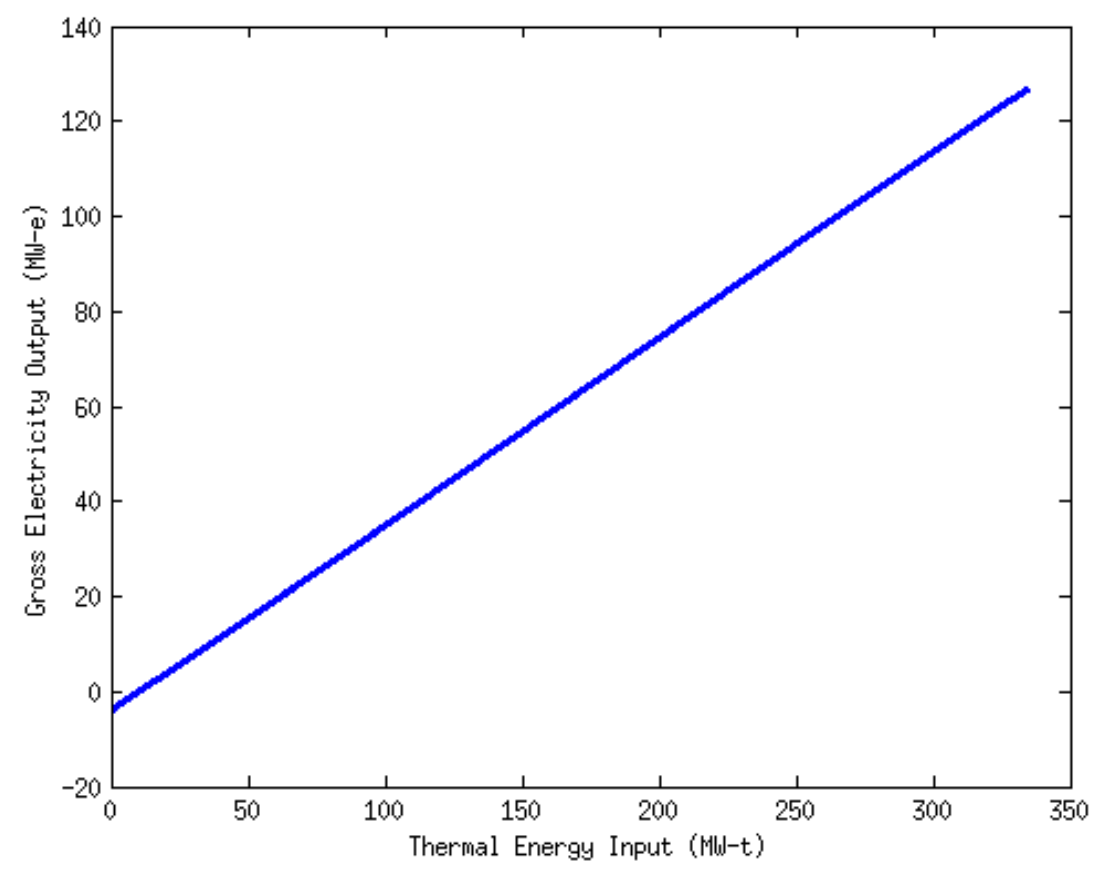

Figure 1. Polynomial heat-rate curve in SAM

The output given by the function in Figure 1 is gross electricity production, and does not account for the parasitics of various components in the CSP plant. These parasitics include energy expended for operating the HTF pumps in the TES system, the cooling tower, and balance of plant. ${ }^{10}$ As with the heat-rate curve, these parasitics are represented as third-order polynomials in SAM. Our model combines cooling tower and balance of plant parasitics into a single power block parasitic. The HTF parasitics are modeled separately because they are a function of the amount of energy taken out of TES, while the other parasitics are a function of gross power block generation. Figures 2 and 3 show the polynomial representation of the parasitics in SAM, as well as the piecewise-linear approximations used in our model. SAM also includes an operating cost estimate of $\$ 0.70$ per MWh-e generated, which is included in the objective function of the dispatch model.

\footnotetext{
${ }^{10}$ Parasitics such as HTF pumps are also associated with operating the solar field. These parasitics are already accounted for and are netted out of the hourly thermal energy data we input from SAM into our dispatch model.
} 


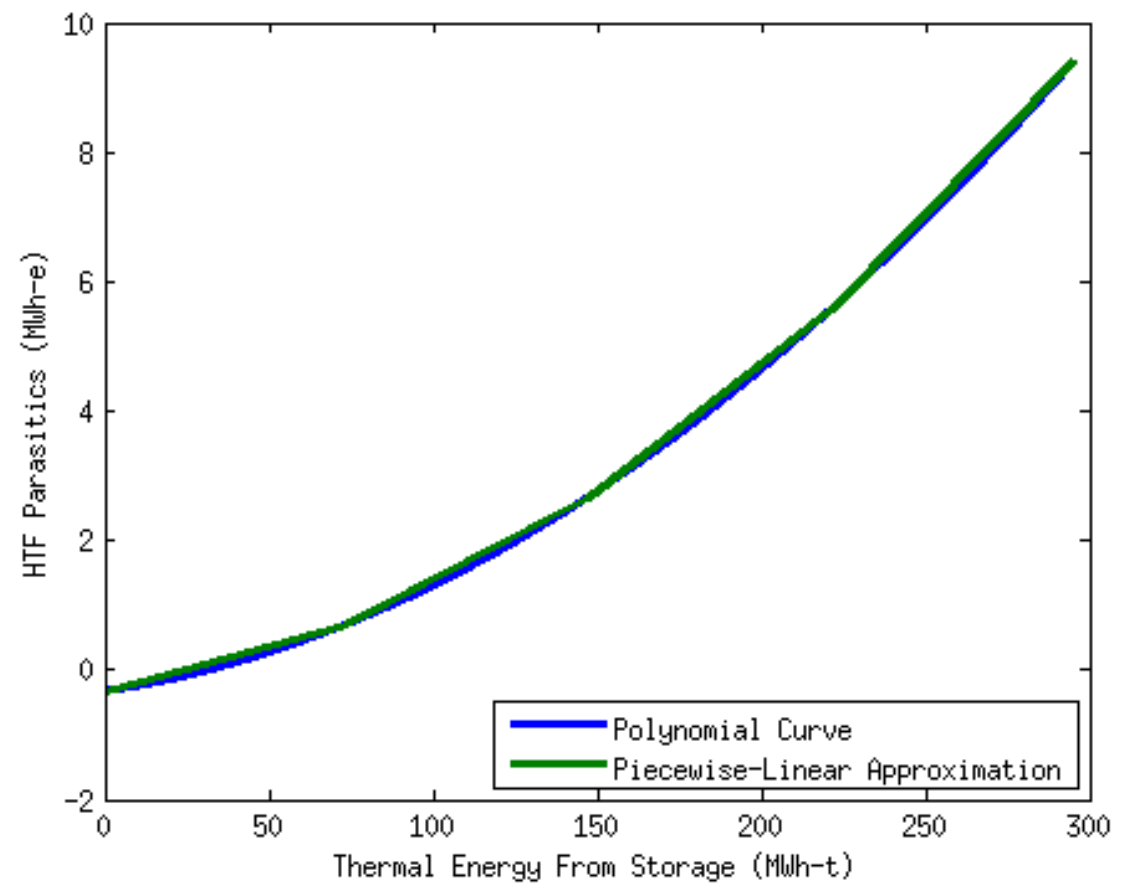

Figure 2. Polynomial representation of HTF parasitics in SAM and piecewise-linear approximation in dispatch model

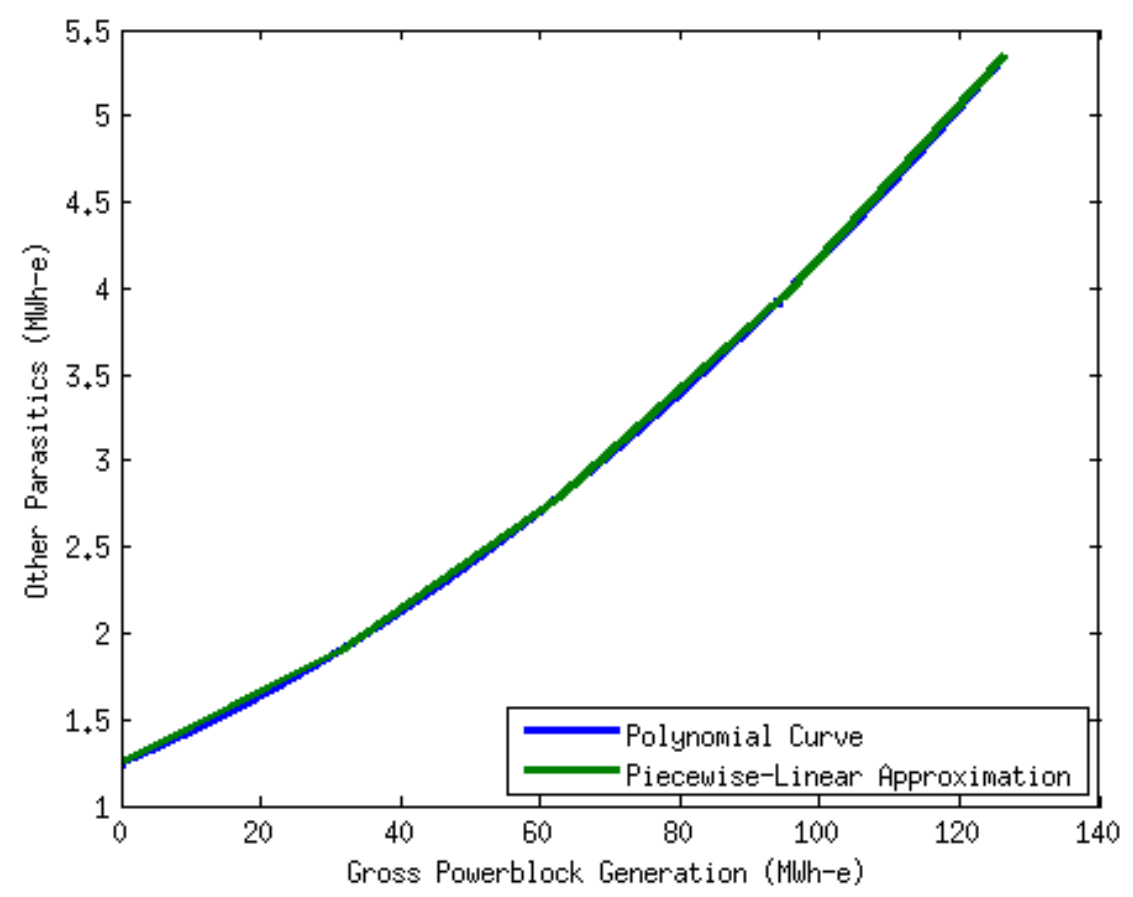

Figure 3. Polynomial representation of power block parasitics in SAM and piecewise-linear approximation in dispatch model 


\section{Operating Profits of CSP Plants with TES in Energy-Only Markets}

As discussed in Section 1, the addition of TES to a CSP plant provides three separate sources of value: energy, capacity, and ancillary services. Our analysis first considers the case of a CSP plant used solely to sell energy into the wholesale market. As discussed in Section 2, we use realtime energy price data from the CAISO and ERCOT market for the Daggett and Texas CSP plants, and we use load lambda data for CSP plants in Arizona and New Mexico, where restructured wholesale markets do not exist. Our analysis first considers the case of a CSP plant operated with perfect foresight of future solar availability and energy prices. Following Sioshansi et al. (2009) the optimization is done one day at a time using a rolling two-day planning horizon. Thus, we assume that dispatch decisions are made one day at a time; however, the next day's energy prices and solar availability are accounted for in making dispatch decisions each day. This use of a two-day planning horizon ensures that energy in TES at the end of the day has carryover value. Without this use of a two-day optimization horizon, energy would never be kept in TES at the end of a day because it would have no value. Figure 4 shows an example dispatch of a CSP plant at the Texas site with six hours of TES and a solar multiple of 2.0 over the course of a winter day, along with available energy from the solar field and hourly energy prices. The figure shows a typical winter price profile, which has highest demand and prices at the beginning and end of the day. The figure shows that the dispatch follows expected patterns, using energy storage for both the morning and evening demand and price peaks. For instance, in the morning (hours eight through 10) the power block is operated with energy from TES, which was carried over from the previous day to catch the high early-morning prices. The power block is shutdown in hours 15 and 16, when energy prices are relatively low, and the solar field energy is put into TES. The plant then provides energy in the evening peak, using both energy from the solar field and energy from storage. 


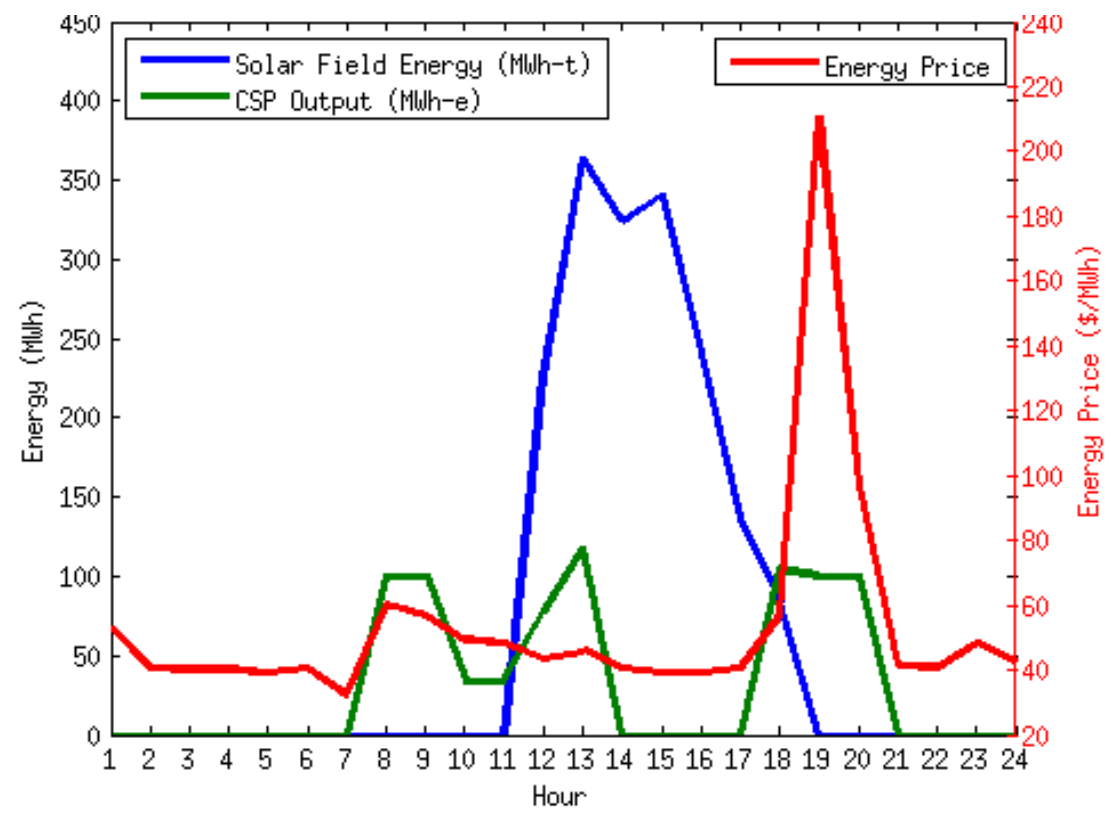

Figure 4. Sample dispatch of a CSP plant with six hours of TES and a solar multiple of 2.0 at Texas site

Figures 5 through 8 show the operating profits of CSP plants with different-sized solar fields and different amounts of TES at the four CSP sites described in Table 1. The figures highlight the fact that the value of a CSP plant can vary significantly by location, with a CSP plant at the Arizona site earning about $60 \%$ of the operating profits of the Texas plant. The figures also show how the operating profits vary with plant size. At all of the sites, the value of TES tapers off at about six to eight hours of storage. Moreover, we see that increasing the size of the solar field only yields noticeable profit increases if sufficient TES is available to shift the solar resource to periods with less available sunlight. 


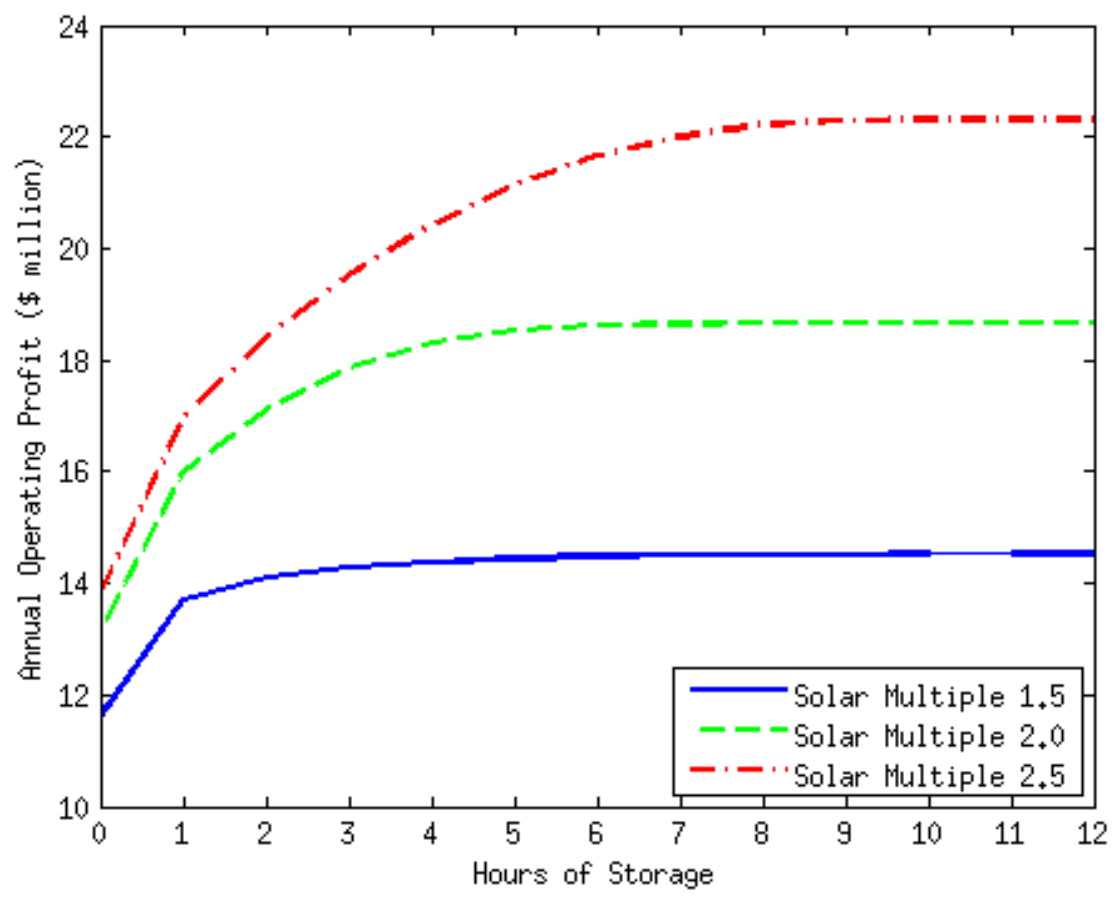

Figure 5: Annual operating profits of a CSP plant at Arizona site

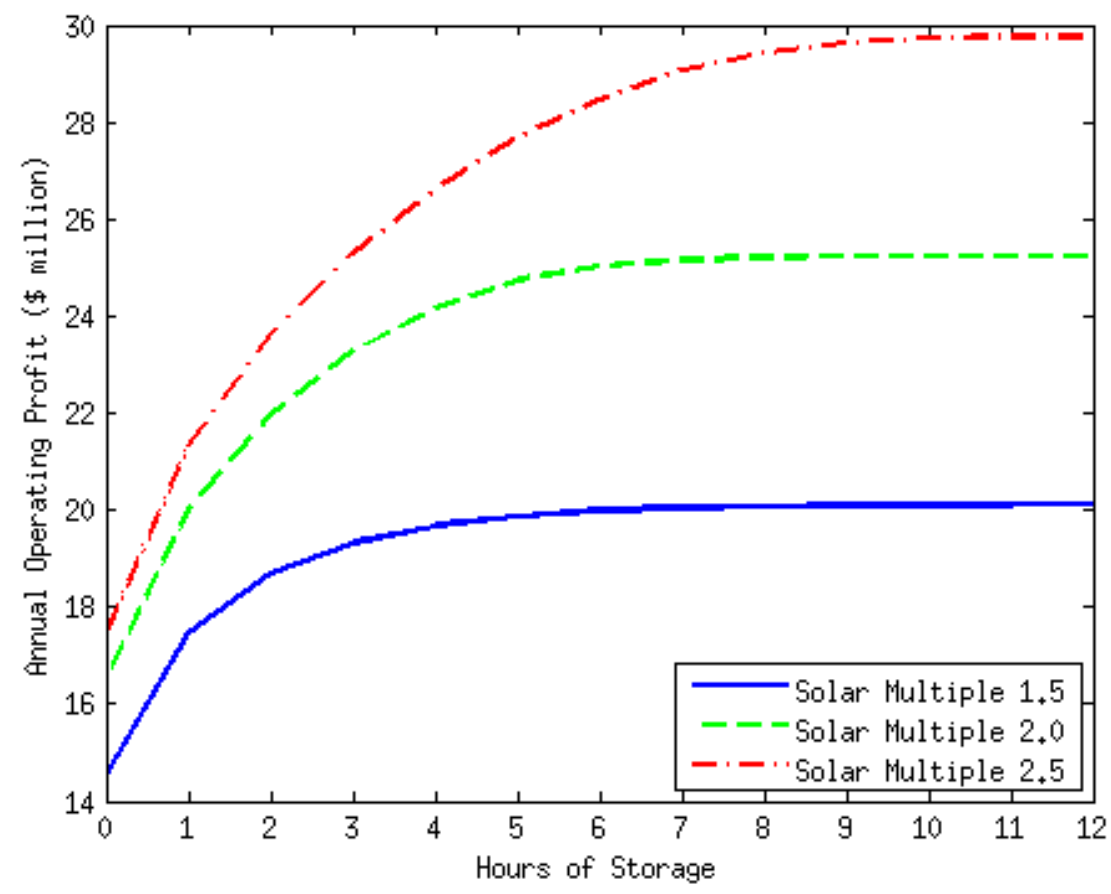

Figure 6: Annual operating profits of a CSP plant at Daggett site 


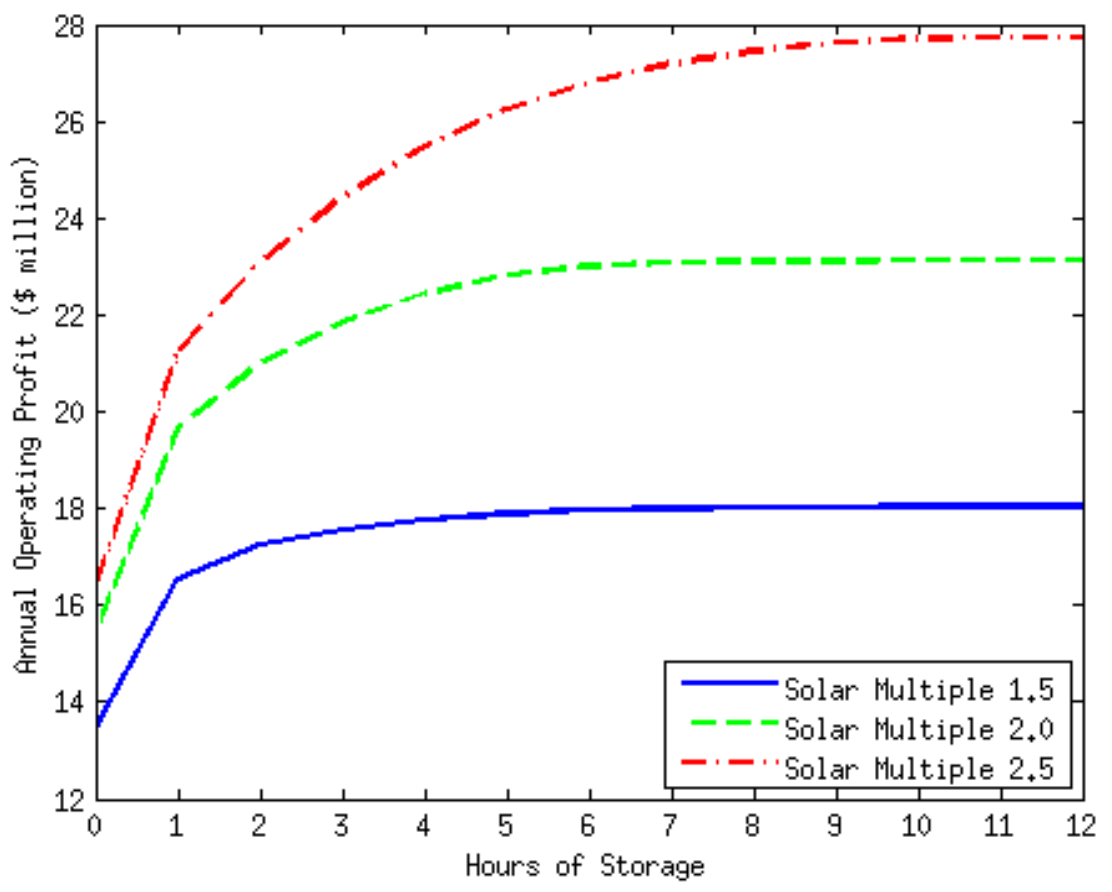

Figure 7: Annual operating profits of a CSP plant at New Mexico site

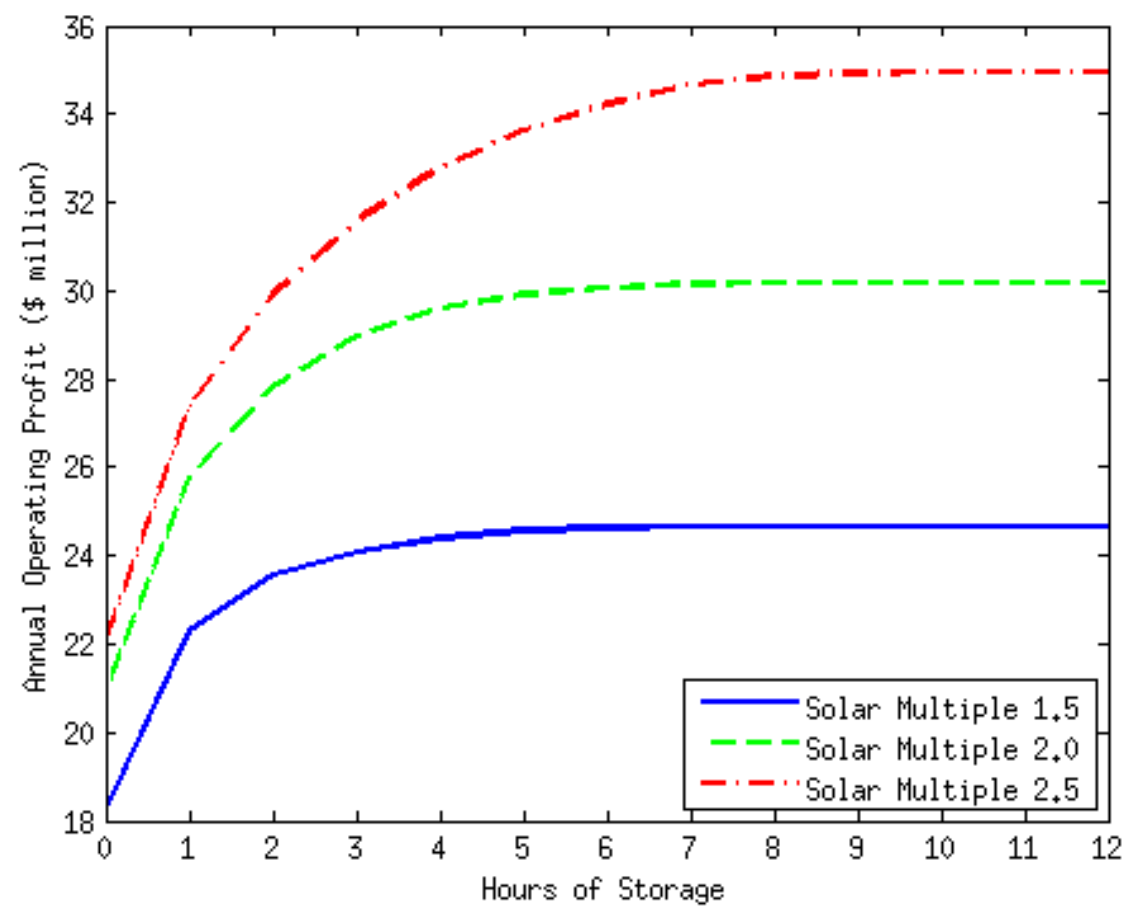

Figure 8: Annual operating profits of a CSP plant at Texas site 
By comparing the average electricity price and the total annual thermal energy produced by different-sized CSP plants, Table 2 shows the underlying cause of the differences in the operating profits of the CSP plants at the different sites. The table shows that the price of energy tends to be more important in determining the profitability of a CSP plant than the amount of solar energy available. Indeed, the Texas site produces the least amount of solar energy, yet the relatively high price of electricity makes it the most profitable site. The table also shows that because of the coincidence of solar insolation with normal load patterns, CSP without TES is between $7 \%$ and $35 \%$ more valuable than the average price of electricity in the cases evaluated. The table further shows that adding TES increases this value by an additional $7 \%$ to $16 \%$.

Table 2: Solar Energy Available and Average Price of Energy for Different CSP Sites

\begin{tabular}{|c|c|c|c|c|c|c|}
\hline \multirow[b]{2}{*}{ CSP Site } & \multirow[b]{2}{*}{$\begin{array}{l}\text { Solar Field } \\
\text { Energy with } \\
\text { Solar Multiple } \\
2.0 \text { (GWh-t) }\end{array}$} & \multirow[b]{2}{*}{$\begin{array}{l}\text { Average } \\
\text { Energy Price } \\
(\$ / M W h)^{11}\end{array}$} & \multicolumn{2}{|c|}{$\begin{array}{c}\text { Average CSP Selling Price } \\
\text { (\$/MWh) }\end{array}$} & \multicolumn{2}{|c|}{$\begin{array}{c}\text { Annual Operating Profits } \\
\text { (\$ million) }\end{array}$} \\
\hline & & & $\begin{array}{l}\text { Solar Multiple } \\
1.5, \text { No TES }\end{array}$ & $\begin{array}{l}\text { Solar Multiple } \\
\text { 2.0, Six Hours } \\
\text { TES }\end{array}$ & $\begin{array}{l}\text { Solar Multiple } \\
1.5, \text { No TES }\end{array}$ & $\begin{array}{l}\text { Solar Multiple } \\
\text { 2.0, Six Hours } \\
\text { TES }\end{array}$ \\
\hline Arizona & 1,150 & 41.2 & 47.0 & 50.5 & 11.6 & 18.6 \\
\hline Daggett & 1,181 & 55.9 & 58.5 & 67.9 & 14.5 & 25.0 \\
\hline New Mexico & 1,088 & 57.3 & 61.2 & 66.2 & 13.5 & 23.0 \\
\hline Texas & 961 & 66.4 & 89.4 & 98.4 & 18.2 & 30.1 \\
\hline
\end{tabular}

The energy-related value of TES is actually derived from two sources. First, TES allows more of the energy collected by the solar field to be used by placing excess energy that would overload the power block into TES for future use, which then allows a larger solar field to be used with a power block. The second value of TES is that it allows generation to be shifted from periods with lower prices to those with higher prices. Figure 9 demonstrates these two effects for a CSP plant in Texas with a solar multiple of 2.0. It shows that as TES is added to the CSP plant, more solar field energy is able to used, with this benefit of TES flattening at about four hours of storage. Moreover, the figure shows that adding TES helps increase the average selling price of energy from the CSP plant, because the TES allows generation to be shifted between hours. This use of TES increases the average selling price of energy from the CSP plant by about $\$ 5 / \mathrm{MWh}$ with three hours of storage. Figure 10 summarizes these two effects of adding TES to a CSP plant by showing the marginal annual value of each incremental hour of storage. As suggested by Figure 9, the first two hours of TES are highly valuable because of both the generation-shifting and the increased use of solar energy, with the marginal value of storage nearly flattening after eight hours of TES; this is because with this amount of storage the generation-shifting capability of TES has been exhausted and nearly all of the energy from the solar field can be used.

\footnotetext{
${ }^{11}$ The average given is the simple average, not a load-weighted average.
} 


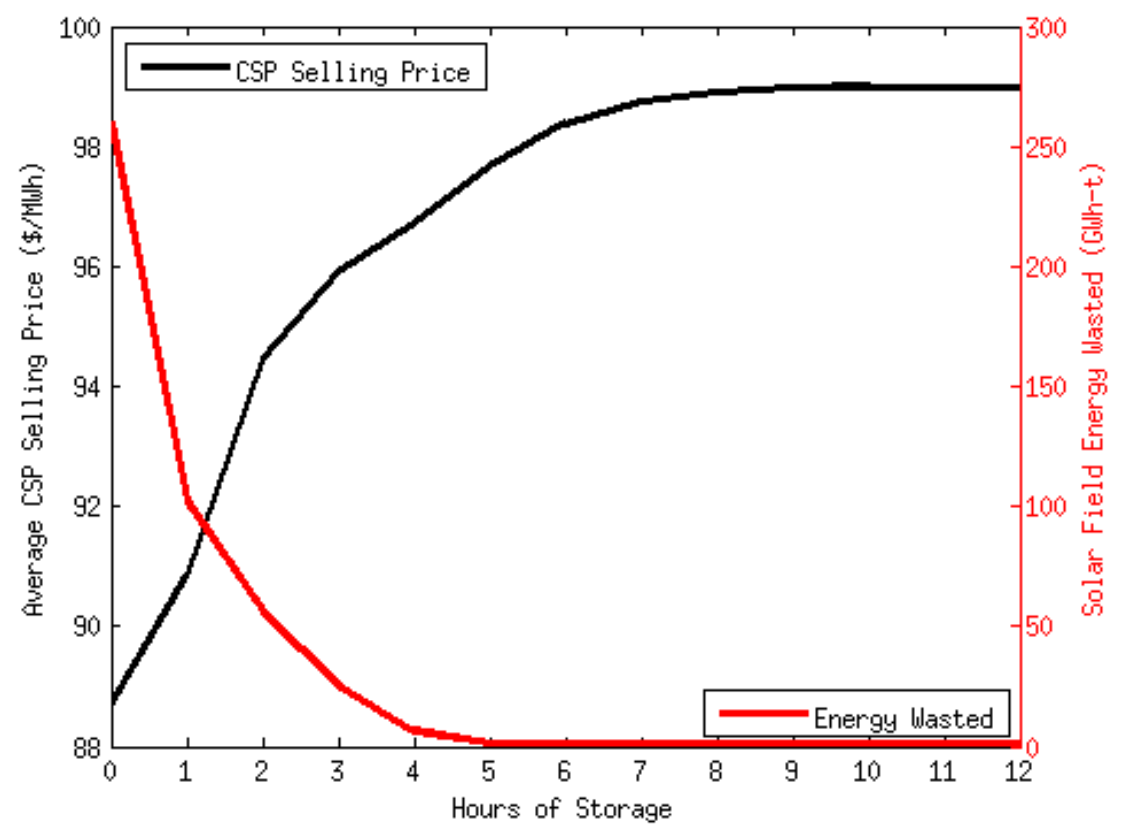

Figure 9. Average selling price of energy (\$/MWh) and solar field energy wasted (GWh-t) for a CSP plant at Texas site with solar multiple of 2.0

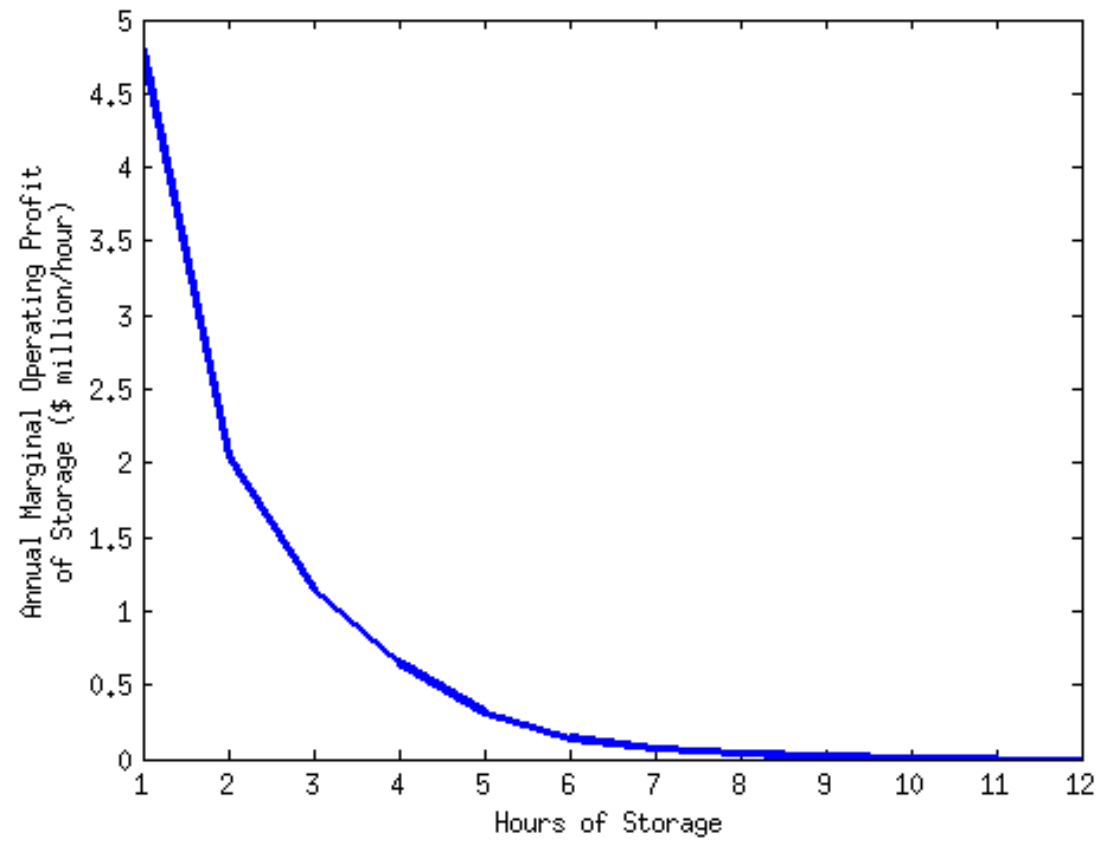

Figure 10. Marginal annual value of each incremental hour of storage for a CSP plant at Texas site with solar multiple of $\mathbf{2 . 0}$ 


\section{Sensitivity of CSP Profits to Base Case Assumptions}

The results presented thus far represent a base case with a set of assumptions regarding the optimization horizon, perfect foresight of solar availability and energy prices, the markets in which the CSP plant participates, and the availability of water for wet cooling of the power block. We now examine the effect of relaxing these base assumptions on the profitability of CSP and the value of TES.

\subsection{Impact of Optimization Horizon}

The results presented in Section 3 assume that the CSP plant would be dispatched using a rolling one-day optimization period (we also assume that each one-day planning problem would account for the second day). These assumptions allow generation to be shifted between hours within a day, and also allow energy to be stored at the end of each day in anticipation of energy prices the following day. However, these assumptions do not account for the fact that a CSP plant may store energy in anticipation of prices multiple days in the future. For example, Sioshansi et al. (2009) describe a "weekend effect," in which more energy tends to be stored over weekends in anticipation of higher energy prices on weekdays. Considering this weekend effect, our assumption of a one-day planning horizon may understate the potential profitability of a CSP plant, because it does not fully allow for inter-day generation shifting.

We examine the sensitivity of CSP profits by comparing our base case with a one-day planning horizon to one with a rolling one-week planning horizon. As with the one-day model, the weeklong model assumes that the CSP plant has perfect foresight of solar availability and energy prices, and we use an eight-day horizon in the dispatch model to ensure that energy in TES has carryover value at the end of each week. Figure 11 shows the increase in annual operating profits if a CSP plant at the Texas site uses a weeklong planning horizon as opposed to daylong one in its dispatch optimization. The profit increases are given as a percentage of the profits from using a daylong planning period. The figure shows that profits are largely insensitive to the optimization period, with less than a $2.4 \%$ increase in profits from switching to a weeklong optimization period, implying that most of the generation shifting with TES is done either within or between adjacent days. The other sites show even less sensitivity to the optimization horizon - with a maximum of between a $1.2 \%$ increase in profits from using a weeklong optimization horizon at the Arizona site and a $1.3 \%$ increase in profits at the New Mexico site. Also interesting is that the profit increase when using a weeklong optimization period is greatest for a CSP plant configuration with a low solar multiple and more hours of storage. The reason for this result is that with a lower solar multiple, the TES is used less for storing excess solar field energy because there are fewer hours in which the capacity of the power block is binding. Thus, a CSP plant with such a configuration uses TES primarily for shifting generation to higherpriced hours, which will be more sensitive to the planning horizon used. 


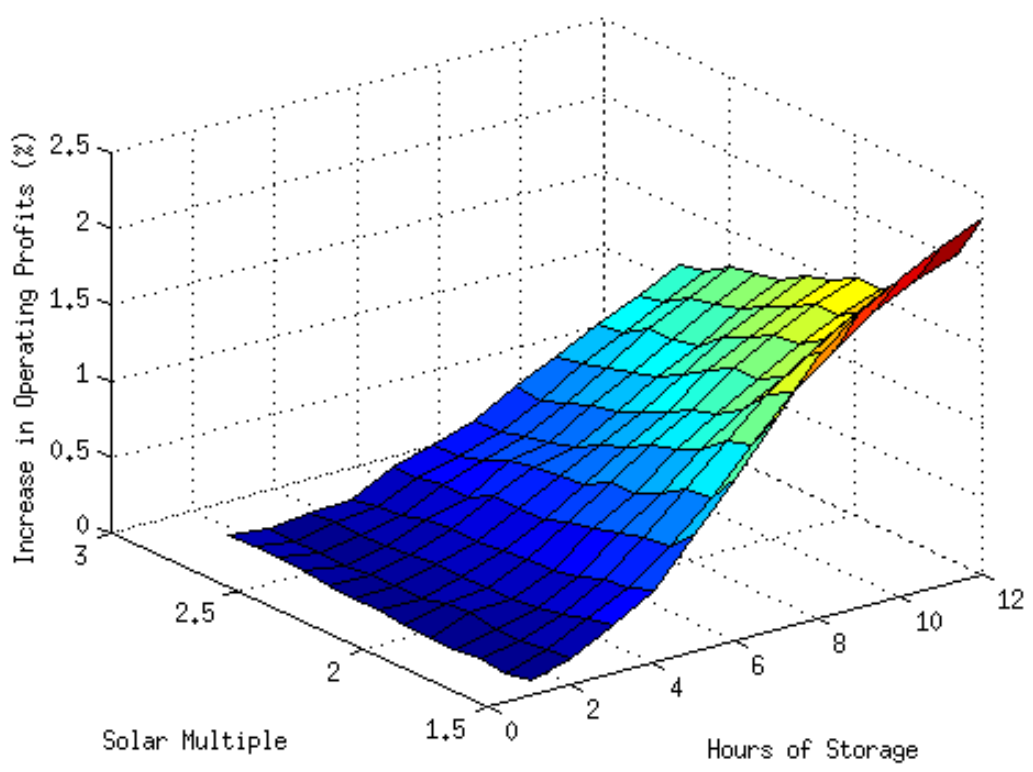

Figure 11. Increase in annual operating profits of a CSP plant at Texas site from using weeklong as opposed to daylong optimization period

Profit increases are given as a percentage of profits with daylong optimization.

\subsection{Impact of Solar Availability and Energy Price Forecasting}

A major assumption of our base case is that the CSP plant will have perfect foresight of future energy prices and solar availability in conducting its optimization, whereas in practice, storage operators will have a forecast of this data to use. Clearly, the profitability of a CSP plant will be closely related to the quality of forecasts that are available to CSP operators, which may vary based on the type of forecasting models used. Rather than trying to approximate the effectiveness of different forecasting techniques in optimizing the dispatch of a CSP plant, we use the "backcasting" technique described in Sioshansi et al. (2009). This backcasting technique assumes that the CSP plant will be dispatched using historical data only. More specifically, we assume the operation of the CSP plant is optimized one hour at a time using a rolling one-day planning horizon. In hour $t$, the dispatch of the CSP plant is optimized using solar availability and price data from the previous 24 hours, assuming that those price and solar patterns will exactly repeat themselves. This daylong dispatch is used to determine the operation of the plant in hour $t$, and the process is repeated. Once the dispatch of the CSP plant is determined, actual price and solar availability data are used to determine the plant's revenues.

Figure 12 compares the operating profits of a CSP plant at the Texas site using the backcasting technique to those achievable with perfect foresight. The results demonstrate that for all CSP plant sizes considered, this backcasting technique earns at least $87 \%$ of the profits that are theoretically attainable with perfect foresight. We conducted the same comparison with the Daggett site, which performed better by earning at least $89 \%$ of the perfect-foresight profits. 


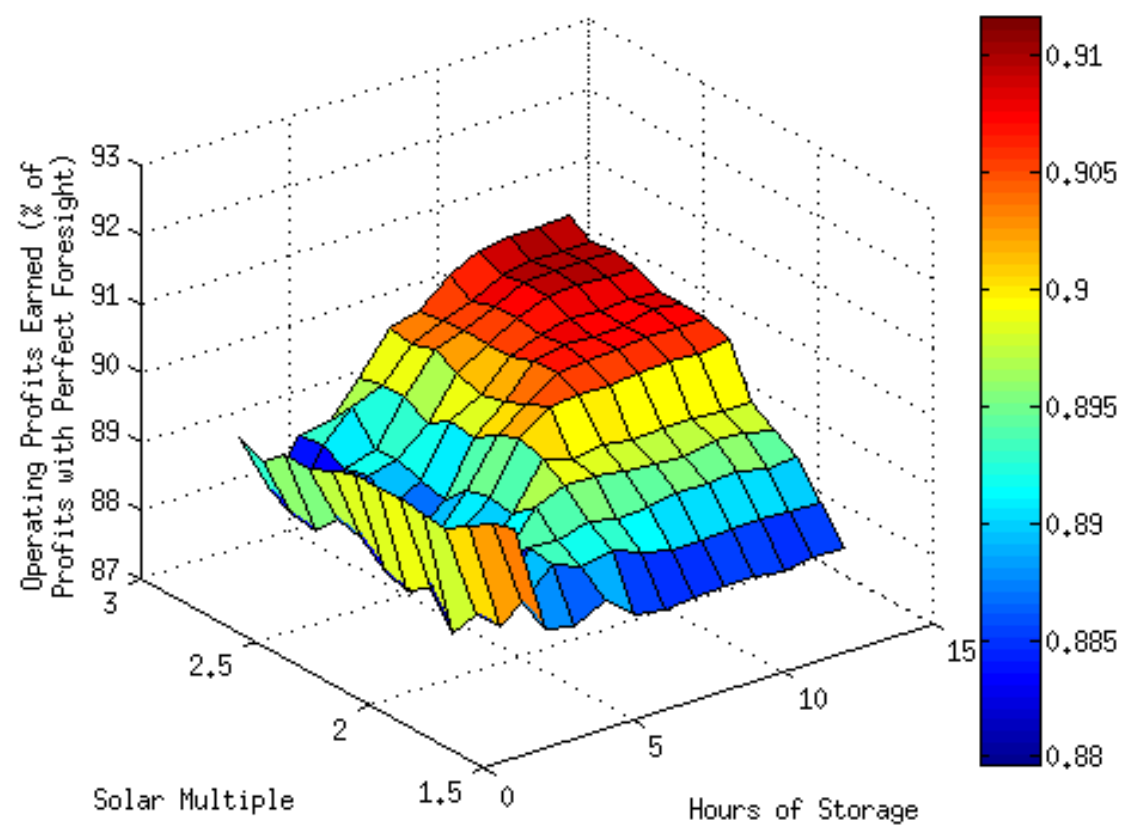

Figure 12. Annual operating profits earned by a CSP plant at Texas site using daily backcasting technique

Profits given as a percentage of profits attainable with perfect foresight.

The relatively good performance of the backcasting technique is not entirely surprising, given that energy prices and solar availability have rather predictable diurnal patterns (Sioshansi et al. 2009). Energy prices tend to peak midday or in the afternoon, and solar availability follows a similar pattern with a midday or afternoon peak (although the peak energy price tends to lag the solar peak by several hours depending on the season). Moreover, while energy prices and solar availability can differ on longer-term bases - for instance, because of seasonal or even annual differences - the use of data from the previous twenty-four hours will tend to capture these effects. Finally, it is important to note that the backcasting technique we examine here does not incorporate any solar or price forecasting in operational decision making. Because weather and prices tend to be fairly predictable, especially on a short-term basis, the value-capture numbers in Figure 12 should be viewed as a lower bound on what can be achieved with the use of forecasting techniques.

\subsection{Impact of Ancillary Service Sales}

The analysis thus far has assumed that the CSP plants will provide only energy, whereas in practice they could also provide ancillary services. Ancillary services typically include regulation, spinning, and non-spinning reserves. Regulation is capacity from a generator that is online, generating, and can quickly be ramped up or down to counterbalance supply deviations on very short, second-long time scales. Regulation is typically deployed using automated controls and is used to maintain supply balance between real-time market settlement periods. Spinning reserve is capacity from a generator that is synchronized with the system, and can provide energy within a longer time frame than regulation does - typically up to thirty minutes. A non-spinning reserve is capacity that can be brought online within a longer time frame than a spinning reserve - typically within half to a full hour-and is deployed to deal with prolonged generator or transmission outages. 
Although these capacity services are used in all of the regions that we consider in our analysis, spinning reserve price data are only available from the CAISO and ERCOT markets. Thus, we only consider spinning reserve sales for the Daggett and Texas CSP sites. We assume that the CSP plant will not provide regulation services or non-spinning reserves because of limitations in the rate at which the power block and TES can be started and ramped. We consider two cases in which the plant can provide either $25 \%$ or $50 \%$ of its generating capacity in the form of spinning reserves. In both cases, we limit the CSP plant such that the total of its energy and spinning reserves sales must be within the power and energy capacity of the plant. These restrictions ensure that if the plant's spinning reserves are deployed in real-time, it can feasibly serve that load in addition to its energy sales. Because spinning reserves are deployed very infrequently (Kempton and Tomić 2005), we do not explicitly model the probability of spinning reserves being deployed or the revenues from that energy being sold.

Figure 13 shows the dispatch of the CSP plant at the Texas site with a solar multiple of 2.0, six hours of TES, and the ability to sell up to $50 \%$ of its capacity in spinning reserves over the same one-day period shown in Figure 4 and contrasts it with CSP operations without spinning reserve sales. Several differences in CSP operations can be noted. For example, the power block is run in hours 15 and 16 in order to allow spinning reserves to be sold. In hours eight through 13 and in hours 18 and 20, the CSP plant produces less energy than the case without spinning reserves sales in order to allow it to sell some spinning reserves.

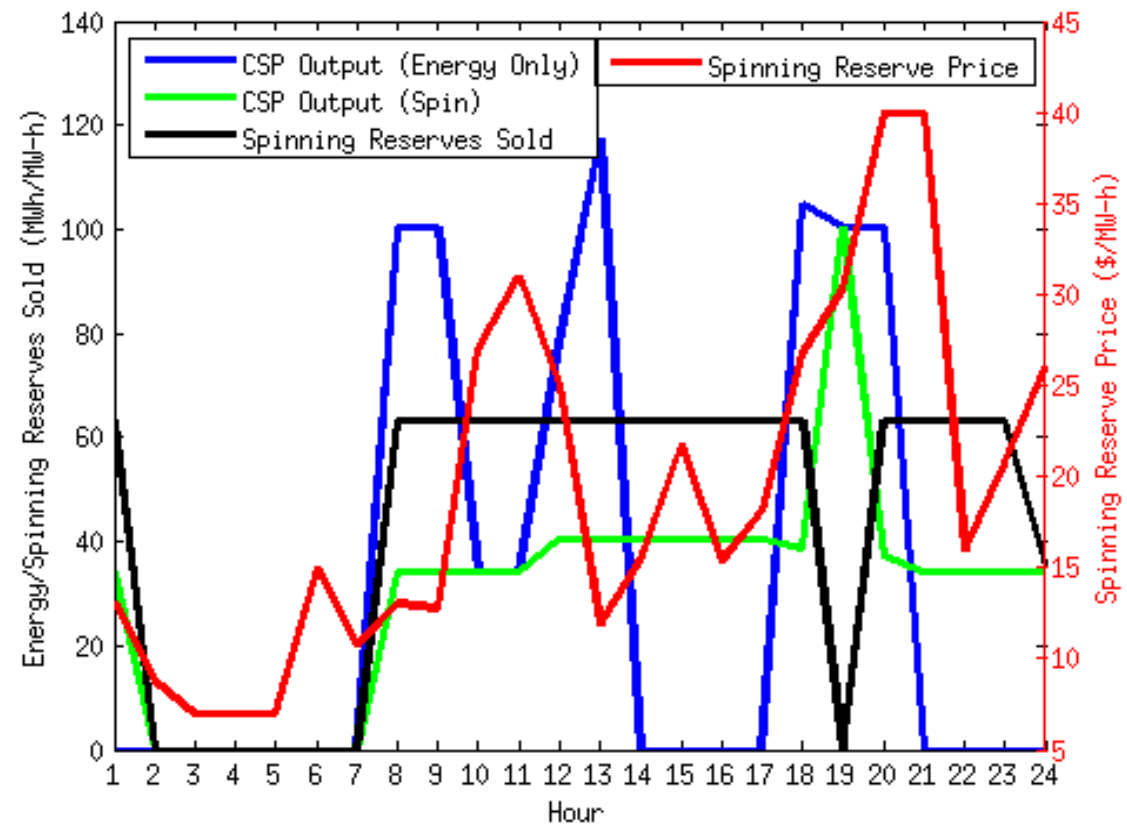

Figure 13. Sample dispatch of a CSP plant with 8 hours of TES and a solar multiple of 2.4 at Texas site when energy and spinning reserve sales are co-optimized

Figures 14 and 15 summarize the effect of allowing the CSP plants to sell spinning reserves on the operating profits of the Daggett and Texas sites, respectively. The figures show the increase in annual profits from the sale of spinning reserves, as a percentage of the profits with energy sales alone. The figures show that, depending on the plant size, these profit increases can be nontrivial. As can be expected, spinning reserve sales are more valuable when the CSP plant is less constrained in how much it can provide. 


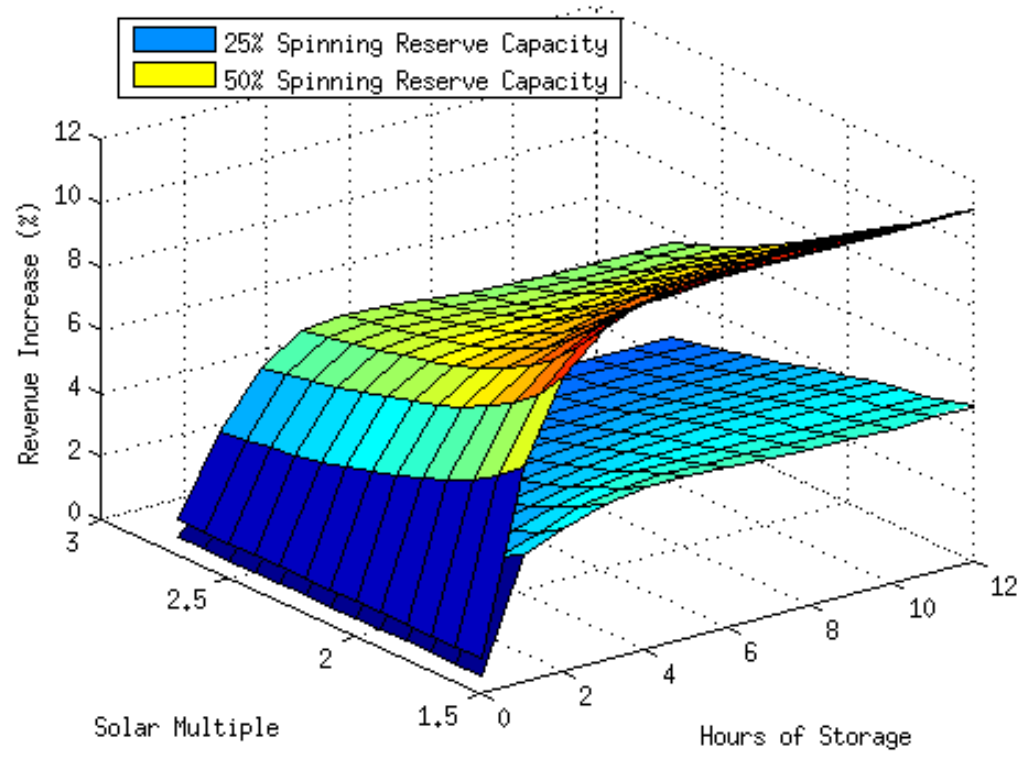

Figure 14. Increase in annual operating profits of a CSP plant at the Daggett site if spinning reserves can be sold

Increase in profits is given as a percentage of profits with energy sales alone.

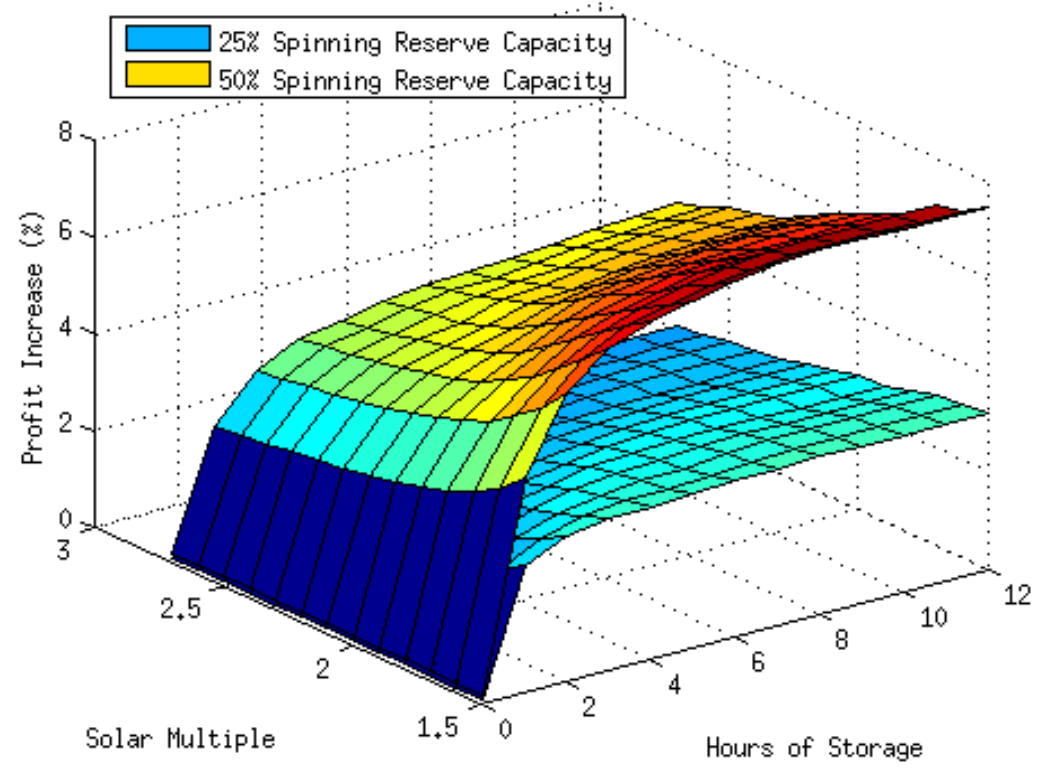

Figure 15. Increase in annual operating profits of a CSP plant at the Texas site if spinning reserves can be sold

Increase in profits is given as a percentage of profits with energy sales alone. 


\subsection{Impact of Capacity Credit}

CSP plants, especially those with TES, will generally provide capacity to the system, which reduces the need for other capacity to be built or procured by the utility, load-serving entity, or system operator. Properly valuing this capacity can pose some difficulties in electricity markets, however, as capacity is not necessarily priced in the market and market distortions can suppress these prices. In theory, restructured energy-only markets - such as the CAISO or ERCOT markets - value capacity through scarcity pricing, whereby prices increase with loads to reflect the cost of capacity constraints. Thus, in such a market, the value of capacity should be captured in energy prices. In practice, however, price caps and other regulatory interventions in the market tend to suppress energy prices, and as a result, capacity may not be properly priced in the market. ${ }^{12}$ Vertically integrated markets, such as those in Arizona and New Mexico, pose an even greater problem in estimating the value of capacity, because the load lambda data we use as proxies for energy prices do not capture any of the value of capacity.

Because capacity is not properly valued in the energy prices used in our analysis, we use the capital cost of a new gas combustion turbine to compute a proxy for the value of capacity. US DOE (2008) estimates the current capital cost of a combustion turbine to be $\$ 625 / \mathrm{kW}$, which translates to a cost of $\$ 68.75$ million for a $110 \mathrm{MW}$ turbine. We can translate this capital cost of a combustion turbine into an annual cost of capacity by using an annual capital charge rate (CCR) that captures all financing parameters and other costs that would go into building such capacity. Following Denholm and Sioshansi (2009), we assume an 11\% CCR, which gives an annual cost of $\$ 7.56$ million for a $110 \mathrm{MW}$ combustion turbine. If the availability of a CSP plant equals that of a combustion turbine, this value of $\$ 7.56$ million represents the capacity value of a CSP plant, which represents a $25 \%-41 \%$ increase in the annual value of a CSP plant with TES compared to the base values in Table 2 .

In practice, the annual capacity value of a CSP plant would be some fraction of this $\$ 7.56$ million, depending upon the actual availability of the CSP plant. The availability of a CSP plant will depend on many factors, such as its scheduled and forced outage rate, and the availability of thermal energy from the solar field and TES. While solar field energy is fixed, the availability of energy from the TES will depend upon the dispatch of the plant. Depending on whether the CSP plant is being given a capacity payment and how those payments are determined, the dispatch of the plant could be altered to maximize the sum of energy and capacity revenues. Further work is needed to assess the actual capacity value of CSP plants as a function of location and storage size.

\subsection{Impact of Power Block Dry Cooling}

Our analysis thus far has assumed that the CSP plants will use a wet-cooled power block.

Because of the arid climate of the southwestern United States, the net effect of dry cooling on the profitability of the CSP plants should be considered. Dry cooling the power block tends to increase cooling tower energy losses, with the efficiency reduction depending upon the ambient temperature. This decrease in efficiency tends to increase the value of TES because high ambient temperatures (which give greater efficiency losses with dry cooling) will tend to be correlated

\footnotetext{
${ }^{12}$ Even in the ERCOT market, which has a much higher price cap than the CAISO market, Sioshansi and Oren (2007) suggest that the threat of regulatory intervention has served to suppress energy prices below levels that profitmaximizing behavior would support.
} 
with the availability of solar energy. Without TES, the solar energy must be put into the power block, which will produce less energy because of cooling losses. With TES, however, energy from the solar field can be stored and generation can be shifted to hours later in the day when ambient temperatures are reduced. SAM accounts for dry cooling energy losses by multiplying gross power block output by a term that is a fourth-order polynomial function of the ambient temperature. We model dry-cooling energy losses in the same manner, and we use the correction factors from SAM as an input to our dispatch model.

Figure 16 shows the annual operating profit loss from using a dry- as opposed to wet-cooled CSP plant at the Texas site, and Figure 17 summarizes the effect at the four sites for CSP plants with a solar multiple of 2.0. As the two figures show, dry cooling can have a noticeable effect on CSP profits, especially for smaller-sized plants. The figures show that the profit losses are highest for CSP plants without TES (or with very little TES). This greater profit reduction is because with TES, generation can be shifted to hours with lower efficiency losses from dry cooling (i.e., hours with lower ambient temperatures). Figure 18 further demonstrates this phenomenon by showing the reduction in net electrical generation of dry-cooled CSP plants with a solar multiple of 2.0 at the four sites as a function of hours of TES. This figure show that adding an hour of storage results in nearly a $0.5 \%$ increase in output from a dry-cooled CSP plant, with incremental storage beyond the first hour giving further increases. One concern with this use of TES in a dry-cooled CSP plant is that market operators may view the shifting of generation to periods with lower ambient temperatures as an attempt by the CSP operator to exercise market power and manipulate energy prices by withholding capacity. While some market monitors may have such a view, this use of TES can be likened to the withholding of water by a hydroelectric or other energy-limited generator, as is described by Lu et al. (2004).

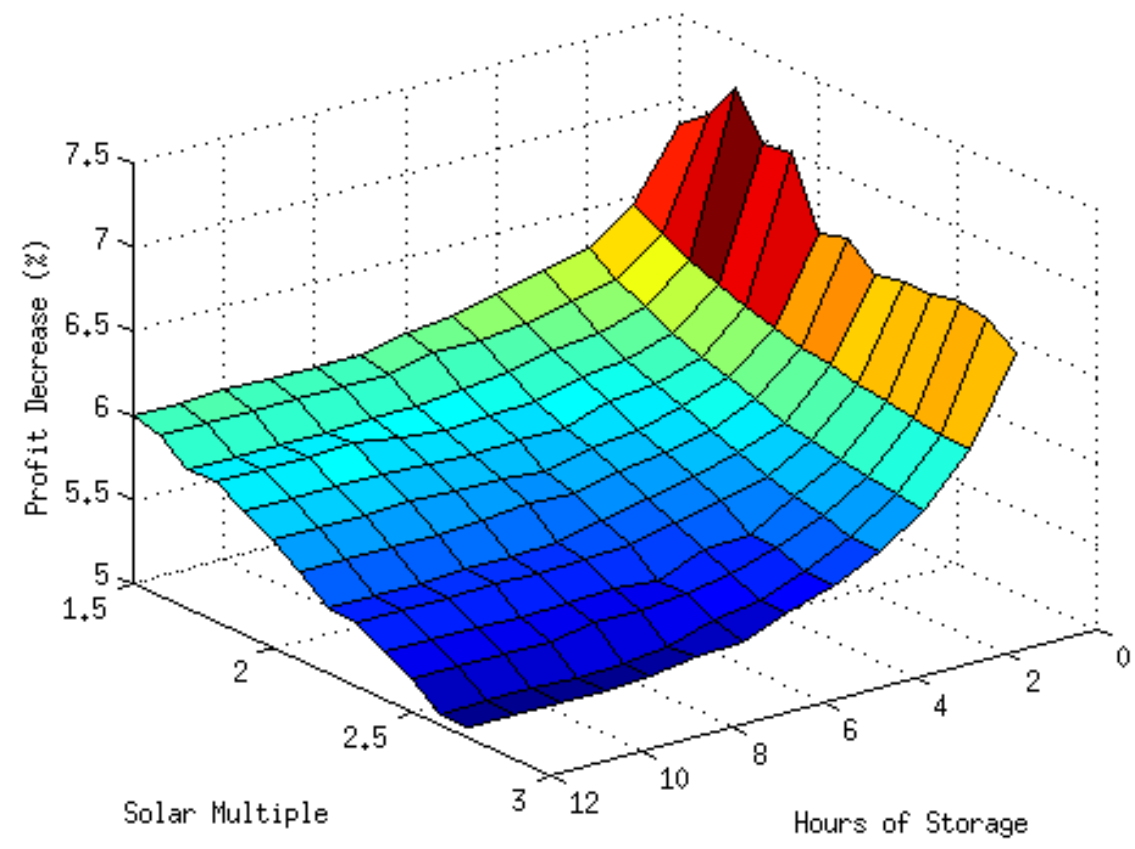

Figure 16: Annual operating profit reduction of a dry-cooled CSP plant at Texas site

Profit reductions are given as a percentage of profits with wet cooling. 


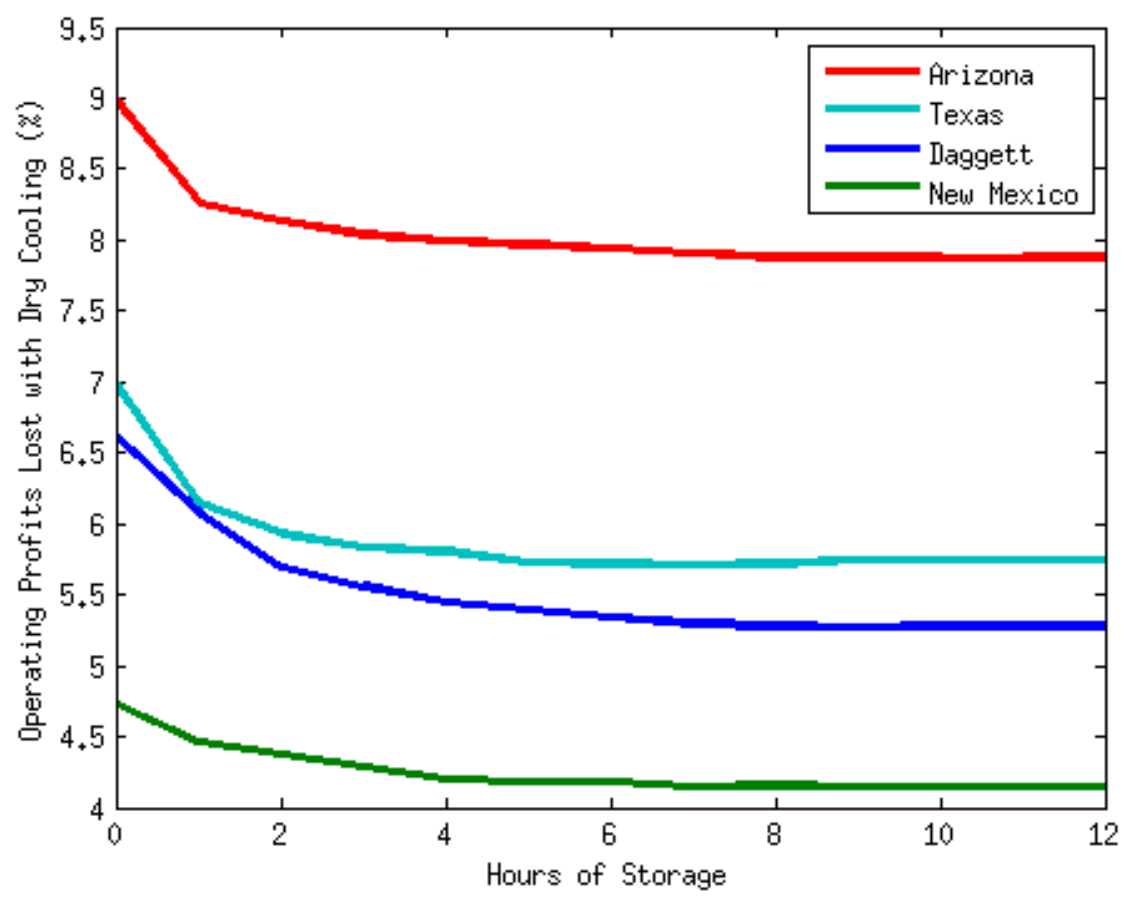

Figure 17. Net operating profits lost from dry-as opposed to wet-cooled CSP plants with a solar multiple of $\mathbf{2 . 0}$

Profit losses given as a percentage of profits with wet cooling.

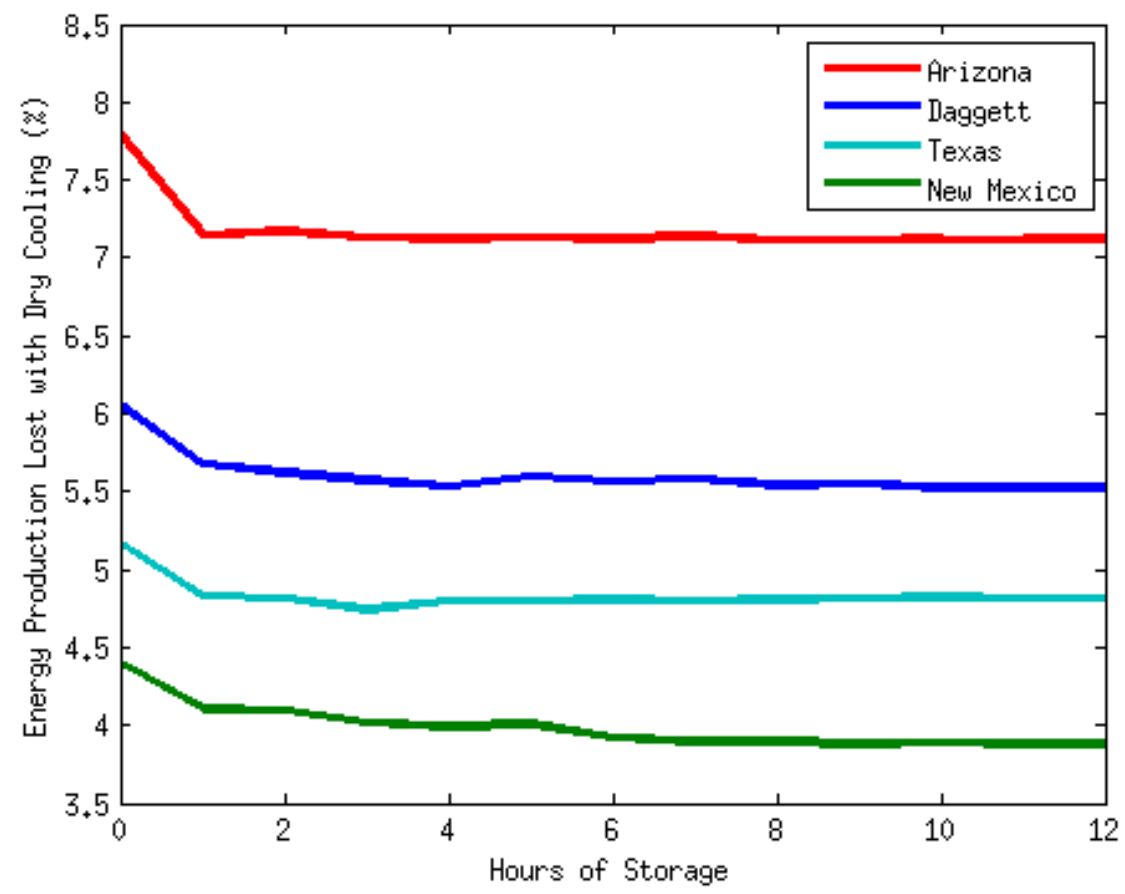

Figure 18. Net energy production lost from dry- as opposed to wet-cooled CSP plants with a solar multiple of $\mathbf{2 . 0}$

Production losses given as a percentage of net energy production with wet cooling. 


\section{Break-Even Cost of CSP Plants}

Our analysis thus far has only considered operating profits (i.e. profits from energy or ancillary service sales less variable operating costs). A complete analysis of the value of CSP and TES must trade operating profits against the capital costs of the plant. This analysis would in turn, require (1) multiple years of energy price and solar data to determine the operating profits of the plant over its lifetime and (2) knowledge of the present and future costs of CSP plants with various amounts of energy storage.

The price of large-scale CSP is still highly uncertainty because of large fluctuations in commodities prices and the potential for substantial cost reductions from engineering and manufacturing improvements. Furthermore, the overall cost competitiveness of CSP will depend on changes in fuel prices and carbon policies. Instead of evaluating the overall economics of CSP in this analysis, we examine the cost competitiveness of the TES component. This type of analysis can tell us whether the additional benefits of TES found in this analysis exceed current and future cost estimates. Moreover, if the benefits of TES are seen to exceed these cost estimates, the value of TES above its cost can help to increase the relative cost competitiveness of the entire CSP plant.

Stoddard et al. (2006) present estimates of present and future TES costs in 2005 dollars, which can be directly compared to the operating profits estimated thus far, because these estimates used 2005 energy price and load lambda data. We use the 2009 cost estimates for present costs and the 2015 estimates for future costs. We assume that without TES, the solar field has a solar multiple of 1.5 and with TES it has six hours of storage and a solar multiple of 2.0, which reflects the fact that with TES the size of the solar field can be increased relative to the power block. We scale the costs of the TES and the solar field because the analysis in Stoddard et al. (2006) assumes a $100 \mathrm{MW}$-e power block for the 2009 CSP plant and a $200 \mathrm{MW}$-e power block for the 2015 CSP plant, whereas we assume a $110 \mathrm{MW}$-e power block throughout our analysis. These assumptions give an estimated present cost of $\$ 156.3$ million for TES (plus the additional solar field cost) and a cost of $\$ 117.6$ million in the future. We also assume that the CSP plant will be eligible for an investment tax credit (ITC) of either $30 \%$ or $10 \%$. The $30 \%$ reflects the current ITC for solar generators, whereas the $10 \%$ reflects a potential future scenario in which the ITC is reduced.

Table 3 summarizes the year-1, break-even cost and return on investment of the TES component of the CSP plant. The break-even cost is defined as the maximum overnight cost of TES, which is justified by the increase in year-1 operating profits of the CSP plant (using an 11\% CCR). The return on investment is defined as the percentage of the annual cost of the TES component (based on the cost estimates from Stoddard et al. (2006) and an 11\% CCR) that is recovered by the increase in year-1 operating profits of the CSP plant. Thus, a return of investment of $100 \%$ or greater indicates that the TES "pays for itself” through higher energy revenues. Clearly, whether the increased revenues from TES will justify the cost of TES will be highly sensitive to the site of the CSP plant, ITC rate, and cost of the TES, but substantial cost reductions appear to be necessary to justify the addition of TES based on energy sales alone. 
Table 3: Year-1 Break-Even Cost and Return on Investment of TES Using Base Case Profit and Cost Assumptions

\begin{tabular}{lcccccc}
\hline & \multicolumn{2}{c}{$\begin{array}{c}\text { Break-even Cost } \\
\text { (\$ million) }\end{array}$} & \multicolumn{4}{c}{ Return on Investment (\%) } \\
& \multicolumn{2}{c}{ Present Cost } & \multicolumn{2}{c}{ Future Cost } \\
CSP Site & $\mathbf{3 0 \%}$ ITC & $\mathbf{1 0 \%}$ ITC & $\mathbf{3 0 \%}$ ITC & $\mathbf{1 0 \%}$ ITC & $\mathbf{3 0 \% ~ I T C}$ & $\mathbf{1 0 \%}$ ITC \\
\cline { 2 - 7 } Arizona & 90.9 & 70.7 & 58.1 & 45.2 & 77.3 & 60.1 \\
Daggett & 136.4 & 106.1 & 87.3 & 67.8 & 115.9 & 90.2 \\
New Mexico & 123.4 & 96.0 & 78.9 & 61.4 & 104.9 & 81.6 \\
Texas & 154.6 & 120.2 & 98.9 & 76.9 & 131.4 & 102.2 \\
\hline
\end{tabular}

Table 3 does not include the non-energy value of CSP and TES, especially the value of more firm capacity. As discussed in Section 4, the operating profits of CSP can potentially be increased by ancillary service sales or a capacity credit. Table 4 summarizes the break-even cost when accounting for these sources of revenues. The spinning reserves sales case assumes that $50 \%$ of the CSP plant's power capacity can be sold as spinning reserves so long as sufficient energy is available from the solar field or TES. For the Arizona and New Mexico sites, for which we do not have spinning reserve price data, we scale up the break-even cost from the costs in Table 3 based on the increase in the break-even cost of the Daggett and Texas sites-which is a roughly $16 \%$ increase. The capacity credit case assumes that the CSP plant has the same availability as a combustion turbine, which gives an annual capacity value of $\$ 7.56$ million. In practice this availability may be lower, which would reduce the break-even cost, but we use this value to provide an upper bound.

Table 4: Year-1 Break-Even Cost of TES (\$ million) with Spinning Reserves Sales and Capacity Credit

\begin{tabular}{lcccc}
\hline & \multicolumn{2}{c}{ Spinning Reserves Sales } & \multicolumn{2}{c}{$\begin{array}{c}\text { Spinning Reserve } \\
\text { Sales and Capacity Credit }\end{array}$} \\
CSP Site & $\mathbf{3 0 \%}$ ITC & $\mathbf{1 0 \%}$ ITC & $\mathbf{3 0 \%}$ ITC & $\mathbf{1 0 \%}$ ITC \\
\cline { 2 - 5 } Arizona & 105.2 & 81.8 & 203.5 & 158.2 \\
Daggett & 160.7 & 125.0 & 259.0 & 201.4 \\
New Mexico & 142.8 & 111.1 & 241.1 & 187.5 \\
Texas & 176.0 & 136.9 & 274.2 & 213.3 \\
\hline
\end{tabular}

Comparing Table 4 to Table 3 and the cost estimates above shows that TES justifies a greater cost with spinning reserves sales and capacity value. With the $30 \%$ ITC, the revenues from TES are greater than its present cost at the Daggett and Texas sites with spinning reserves sales alone. If the capacity credit is included, TES is justified at all sites. 
Table 5 provides the return on investment of the TES components, considering the ability to provide both spinning reserves sales and capacity credit. In this case, only a $10 \%$ ITC is

evaluated, and in all cases, the return on investment (ROI) is greater than $100 \%$, meaning that the value of TES is greater than its incremental capital cost. As a result, the incremental value above the cost of TES will improve the cost competitiveness of the entire CSP plant.

Table 5: Return on Investment of TES with Spinning Reserves Sales and Capacity Credit and a 10\% ITC

\begin{tabular}{lcc}
\hline & \multicolumn{2}{c}{ Return on Investment (\%) } \\
CSP Site & Present Cost & Future Cost \\
\cline { 2 - 3 } Arizona & 100.9 & 134.1 \\
Daggett & 125.4 & 166.7 \\
New Mexico & 118.7 & 157.3 \\
Texas & 136.4 & 181.3 \\
\hline
\end{tabular}




\section{Conclusions}

This paper presented a detailed analysis of the value of CSP plants with TES in for regions in the southwestern United States. Our results showed how operating profits of CSP plants vary as a function of plant size and location. Locational profit differences were shown to be mainly due to differences in energy prices in the different system operator and utility systems considered, with differences in solar resource being a smaller determinant of CSP value. We showed that TES could increase CSP value both by allowing generation to be shifted to higher-priced hours and by increasing the use of thermal energy from the solar field.

We also showed the effect of relaxing several of our base assumptions on CSP profitability. The operating profits of the CSP plant seemed relatively insensitive to the assumption that TES dispatch decisions are made a day at a time, which suggests that most generation shifting is done either within a day or between adjacent days. Longer-term generation shifting over the course of the week and the so-called "weekend effect" were not noticeably apparent for CSP plants, except for plants with small solar fields and large amounts of storage. We also demonstrated that the perfect foresight of energy prices and solar availability assumed throughout our analysis is a relatively good approximation of actual CSP operations; at least $87 \%$ of the profits with perfect foresight can be attained by using a very simple backcasting technique. We expect that including price and weather forecasts in the dispatch process can further improve the profitability of a CSP plant. We also showed that adding ancillary services sales can increase CSP profits, and we examined the effect of dry cooling - showing that TES can reduce some efficiency losses associated with dry cooling by shifting generation to hours with lower ambient temperatures.

Despite these benefits of CSP, our analysis suggests that with current capital costs, TES cannot be economically justified on energy value alone. However, including the value of ancillary service sales and capacity can increase the cost competitiveness of TES, making it economic in a number of cases and improving the overall economics of CSP. 


\section{References}

Denholm, P. and Sioshansi, R. (2009). "The Value of Compressed Air Energy Storage with Wind in Transmission-constrained Electric Power Systems." Energy Policy 37(8); pp. 31493158. doi:10.1016/j.enpol.2009.04.002

Gilman, P.; Blair, N.; Mehos, M.; Christensen, C.; Janzou, S.; Cameron, C. (2008). Solar Advisor Model User Guide for Version 2.0. NREL/TP-670-43704. Golden, CO: National Renewable Energy Laboratory.

Kempton, W. and Tomić J. (2005). "Vehicle-to-grid Power Fundamentals: Calculating Capacity and Net Revenue." Journal of Power Sources 144(1); pp. 268-279.

doi:10.1016/j.jpowsour.2004.12.025

Lu, N.; Chow, J.; Desrochers, A. (2004). "Pumped-Storage Hydro-Turbine Bidding Strategies in a Competitive Electricity Market." IEEE Transactions on Power Systems 19(2004); pp. 834-841. doi:10.1109/TPWRS.2004.825911

Sioshansi, R.; Denholm, P.; Jenkin T.; Weiss, J. (2009). "Estimating the Value of Electricity Storage in PJM: Arbitrage and Some Welfare Effects." Energy Economics 31(2); pp. 269-277. doi:10.1016/10.1007/s11149-006-9008-6

Sioshansi, R.; Oren, S. S. (2007). "How Good are Supply Function Equilibrium Models: An Empirical Analysis of the ERCOT Balancing Market.” Journal of Regulatory Economics 31(1); pp. 1-35. doi: 10.1007/s11149-006-9008-6

Stoddard, L.; Abiecunas, J.; O'Connell, R. (2006). Economic, Energy, and Environmental Benefits of Concentrating Solar Power in California. NREL/SR-550-39291. Golden, CO: National Renewable Energy Laboratory.

US DOE (May 2008). 20\% Wind Energy by 2030: Increasing Wind Energy's Contribution to U.S. Electricity Supply. DOE/GO-102008-2567. Washington, DC: U.S. Department of Energy. 


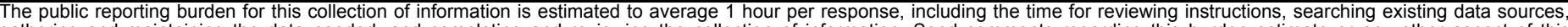

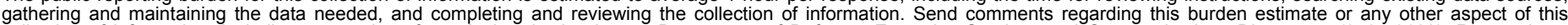

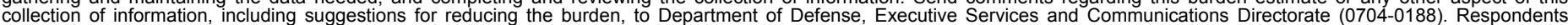

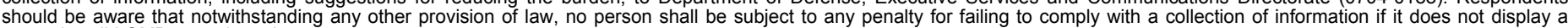

should be aware that notwithstanding

PLEASE DO NOT RETURN YOUR FORM TO THE ABOVE ORGANIZATION.

\begin{tabular}{ll|l}
\hline 1. & $\begin{array}{l}\text { REPORT DATE }(D D-M M-Y Y Y Y) \\
\text { February } 2010\end{array}$ & $\begin{array}{l}\text { 2. } \\
\text { REPORT TYPE } \\
\text { Technical Report }\end{array}$ \\
\hline 4. & $\begin{array}{l}\text { TITLE AND SUBTITLE } \\
\text { The Value of Concentrating Solar Power and Thermal Energy } \\
\text { Storage }\end{array}$
\end{tabular}

3. DATES COVERED (From - To)
February 2010

The Value of Concentrating Solar Power and Thermal Energy 5a. CONTRACT NUMBER

DE-AC36-08-GO28308

5b. GRANT NUMBER

5c. PROGRAM ELEMENT NUMBER

5d. PROJECT NUMBER

NREL/TP-6A2-45833

5e. TASK NUMBER

CP09.3201

5f. WORK UNIT NUMBER
7. PERFORMING ORGANIZATION NAME(S) AND ADDRESS(ES)

National Renewable Energy Laboratory

1617 Cole Blvd.

Golden, CO 80401-3393
8. PERFORMING ORGANIZATION REPORT NUMBER

NREL/TP-6A2-45833

9. SPONSORING/MONITORING AGENCY NAME(S) AND ADDRESS(ES)

10. SPONSOR/MONITOR'S ACRONYM(S) NREL

11. SPONSORING/MONITORING AGENCY REPORT NUMBER

12. DISTRIBUTION AVAILABILITY STATEMENT

National Technical Information Service

U.S. Department of Commerce

5285 Port Royal Road

Springfield, VA 22161

13. SUPPLEMENTARY NOTES

14. ABSTRACT (Maximum 200 Words)

This paper examines the value of concentrating solar power (CSP) and thermal energy storage (TES) in four regions in the southwestern United States. Our analysis shows that TES can increase the value of CSP by allowing more thermal energy from a CSP plant's solar field to be used, by allowing a CSP plant to accommodate a larger solar field, and by allowing CSP generation to be shifted to hours with higher energy prices. We analyze the sensitivity of CSP value to a number of factors, including the optimization period, price and solar forecasting, ancillary service sales, capacity value and dry cooling of the CSP plant. We also discuss the value of CSP plants and TES net of capital costs.

15. SUBJECT TERMS

concentrating solar power; CSP; CSP plant; thermal energy storage; TES; economic value; southwestern United States; Arizona; California; New Mexico; Texas; solar field; energy prices; optimization period; solar forecasting; ancillary service sales; dry cooling

\begin{tabular}{|l|l|l|l|l|l}
\hline \multicolumn{2}{|l|}{ 16. SECURITY CLASSIFICATION OF: } & $\begin{array}{c}\text { 17. LIMITATION } \\
\text { OF ABSTRACT } \\
\text { U. REPORT } \\
\begin{array}{l}\text { Unclassified } \\
\text { Unclassified }\end{array}\end{array}$ & $\begin{array}{l}\text { c. THIS PAGE } \\
\text { Unclassified }\end{array}$ & $\begin{array}{c}\text { NUMBER } \\
\text { OF PAGES }\end{array}$ \\
\hline
\end{tabular}

19b. TELEPHONE NUMBER (Include area code) 